\title{
Phenotypic flexibility in heat production and heat loss in response to thermal and hydric acclimation in the zebra finch, a small arid-zone passerine
}

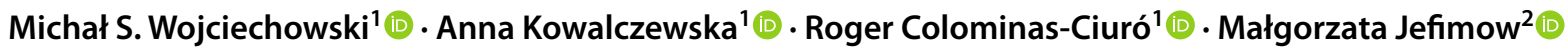

Received: 21 May 2020 / Revised: 21 September 2020 / Accepted: 29 September 2020 / Published online: 18 October 2020

(c) The Author(s) 2020

\begin{abstract}
To maintain constant body temperature $\left(T_{\mathrm{b}}\right)$ over a wide range of ambient temperatures $\left(T_{\mathrm{a}}\right)$ endothermic animals require large amounts of energy and water. In hot environments, the main threat to endothermic homeotherms is insufficient water to supply that necessary for thermoregulation. We investigated flexible adjustment of traits related to thermoregulation and water conservation during acclimation to hot conditions or restricted water availability, or both, in the zebra finch, Taeniopygia guttata a small arid-zone passerine. Using indirect calorimetry, we measured changes in whole animal metabolic rate (MR), evaporative heat loss (EHL) and $T_{\mathrm{b}}$ before and after acclimation to 23 or $40{ }^{\circ} \mathrm{C}$, with different availability of water. Additionally, we quantified changes in partitioning of EHL into respiratory and cutaneous avenues in birds exposed to 25 and $40{ }^{\circ} \mathrm{C}$. In response to heat and water restriction zebra finches decreased MR, which together with unchanged EHL resulted in increased efficiency of evaporative heat loss. This facilitated more precise $T_{\mathrm{b}}$ regulation in heat-acclimated birds. Acclimation temperature and water availability had no effect on the partitioning of EHL into cutaneous or respiratory avenues. At $25{ }^{\circ} \mathrm{C}$, cutaneous EHL accounted for $\sim 60 \%$ of total EHL, while at $40{ }^{\circ} \mathrm{C}$, its contribution decreased to $\sim 20 \%$. Consistent among-individual differences in MR and EHL suggest that these traits, provided that they are heritable, may be a subject to natural selection. We conclude that phenotypic flexibility in metabolic heat production associated with acclimation to hot, water-scarce conditions is crucial in response to changing environmental conditions, especially in the face of current and predicted climate change.
\end{abstract}

Keywords Energy metabolism · Evaporative heat loss $\cdot$ Thermoregulation $\cdot$ Phenotypic flexibility $\cdot$ Passerine

Communicated by G. Heldmaier.

Electronic supplementary material The online version of this article (https://doi.org/10.1007/s00360-020-01322-0) contains supplementary material, which is available to authorized users.

Michał S. Wojciechowski mwojc@umk.pl

1 Department of Vertebrate Zoology and Ecology, Faculty of Biological and Veterinary Sciences, Nicolaus Copernicus University, Toruń, Poland

2 Department of Animal Physiology and Neurobiology, Faculty of Biological and Veterinary Sciences, Nicolaus Copernicus University, Toruń, Poland

\section{Introduction}

Endothermic homeothermy is the ability to maintain relatively constant body temperature over the wide range of ambient temperatures $\left(T_{\mathrm{a}}\right)$ using behavioral and physiological mechanisms of heat production and heat dissipation. In the cold, maximum heat production in resting animals may be as high as nine times basal heat production (Swanson 2010), while in the heat, when operative (Bakken 1992) or air temperature exceeds body temperature $\left(T_{\mathrm{b}}\right)$, birds can dissipate as much as five times as much heat than is produced (O'Connor et al. 2017). However, under such conditions, heat dissipation is possible only via evaporation of water from the body surfaces, both respiratory and cutaneous (for example, Marder and Arieli 1988; McKechnie and Wolf 2004b; Williams and Tieleman 2005). Effective evaporation enables birds to maintain thermal balance even during prolonged acclimation to temperatures as high as $60{ }^{\circ} \mathrm{C}$ (Marder 
and Arieli 1988). Water necessary for thermoregulation is obtained both by intake (drinking and food) and as a byproduct of metabolic processes (metabolic water production) (Jenni-Eiermann and Jenni 2012; Schmidt-Nielsen 1997). Passerines can rely on metabolic water production both during flight in desiccating conditions (Gerson and Guglielmo 2011) as well as during rest when fasting (Rutkowska et al. 2016).

In face of increased probability of unpredictable extreme weather events and increased mean ambient temperatures (IPCC 2014; Meehl and Tebaldi 2004), it was predicted that one of the main threats to endothermic homeotherms is insufficient water supply necessary for thermoregulation as well as the direct risk of lethal hyperthermia (Conradie et al. 2020; McKechnie and Wolf 2010). This indeed seems to be the case for mammals and birds living in subtropical areas (Conradie et al. 2019, 2020; McKechnie and Wolf 2010; Welbergen et al. 2008). However, in response to rapid, often unpredictable changes in abiotic conditions, animals flexibly adjust their physiology to match changes in energy demands (Piersma and Van Gils 2011). Thus, it is legitimate to ask whether acclimation or acclimatization to desiccating conditions may mitigate the risk of dehydration and overheating in response to extreme weather events. In several lark species acclimation to $T_{\mathrm{a}}$ 's within their thermoneutral zone (TNZ) led to decreased basal metabolic rate (BMR) and total evaporative water loss (TEWL), and these changes were species specific (Tieleman et al. 2003; Williams and Tieleman 2000). Larks inhabiting desert areas had lower BMR, TEWL and a lower heat transfer coefficient than birds inhabiting mesic areas (Tieleman et al. 2002a). The very few studies of physiological adjustments of thermoregulation in small passerines indicate that seasonally increased ambient temperatures, often exceeding body temperature, also increased efficiency of evaporative heat loss (EHL) which facilitated maintenance of constant $T_{\mathrm{b}}$ at high $T_{\mathrm{a}}$ 's (Noakes et al. 2016; Oswald et al. 2018). The most striking example of the effect of acclimation to high $T_{\mathrm{a}}$ on the ability to maintain heat balance in birds comes from the classic studies by Marder and co-workers who showed that rock pigeons (Columba livia) flexibly adjusted heat loss by means of evaporation to regulate their $T_{\mathrm{b}}$, which allows them to live and successfully reproduce under extreme desert heat, provided water is available ad libitum (Dawson 2003; Marder 1983; Marder and Arieli 1988; Marder and GavrieliLevin 1987). By increasing cutaneous evaporative water loss (CEWL) rock pigeons protect themselves from hyperthermia, without any noticeable increase in metabolic heat production (Marder and Arieli 1988). It should be noted that Marder and co-workers acclimated rock pigeons to $T_{\mathrm{a}}$ 's exceeding their $T_{\mathrm{b}}$. Similar flexible adjustments of CEWL were also reported in other Columbiformes (McKechnie and Wolf 2004b). However, if drinking water is limited, increased EWL in the heat can lead to greater risk of dehydration. Therefore, it is not surprising that arid-zone larks at moderate $T_{\mathrm{a}}$ 's had both reduced CEWL and respiratory evaporative water loss (REWL) than mesic species (Tieleman and Williams 2002), yet at high $T_{\mathrm{a}}$ 's, this difference disappeared.

Acclimation of house sparrows Passer domesticus to desiccating conditions led to reduced CEWL accompanied by changes in lipid composition in the epidermal stratum corneum (Muñoz-Garcia et al. 2008). These results concur with the considerable reduction in total EWL observed in water-deprived zebra finches (Taeniopygia guttata), a small arid-zone passerine native to Australia (Zann 1996), exposed to moderately high $T_{\mathrm{a}}$ 's (Calder 1964), as well as with a reduction in CEWL in rock pigeons deprived of water for $48 \mathrm{~h}$ (Arad et al. 1987). More detailed knowledge of flexible adjustments in physiology of heat production and dissipation is of key importance for our understanding of the threats of global environmental changes on animal fitness.

In the light of above, we asked what is the pattern of changes in physiology of thermoregulation in small passerine birds in response to prolonged acclimation ( $>30$ days) to hot or desiccating conditions, or both. To address this question, we used zebra finches as a model species. We predicted that in response to high $T_{\mathrm{a}}\left(40^{\circ} \mathrm{C}\right.$ during the active phase, $\alpha$-phase) their metabolic rate (MR) decreases compared to birds acclimated to a $T_{\mathrm{a}}$ below thermoneutrality $\left(23{ }^{\circ} \mathrm{C}\right.$; reported $\mathrm{TNZ}$ of the species is between 30 and $40{ }^{\circ} \mathrm{C}$; Calder 1964, but see present results). Moreover, we expected that desiccating conditions (water deprived for half of the $\alpha$-phase) under both thermal regimes would result in a greater reduction in TEWL than in birds with unlimited access to water. We assumed that the efficiency of heat dissipation in zebra finches with free access to drinking water at high $T_{\mathrm{a}}$ 's would be higher than in those deprived of water and that the threshold for hyperthermia is higher in birds with water available ad libitum. To test these predictions, we measured gas exchange, EWL and $T_{\mathrm{b}}$ before and after acclimation to hot and desiccating conditions. Finally, we aimed to determine whether prolonged acclimation to the above-described conditions would result in changes in the partitioning of TEWL between the respiratory and cutaneous avenues and predicted that in birds acclimated to restricted water availability under both thermal regimes CEWL is lower than in individuals with ad libitum access to water. To test this prediction, we measured CEWL and REWL, at $T_{\mathrm{a}}$ 's below and above thermoneutrality.

\section{Materials and methods}

\section{Animals and experimental design}

We used 36 adult ( 2 years old), male zebra finches Taeniopygia guttata, Vieillot 1817 originating from the 
breeding colony at the Max-Planck Institute for Ornithology Seewiesen, Germany. Birds were transferred to the animal facilities at the Nicolaus Copernicus University in Torun (Poland) 1.5 months prior to the experiments. Throughout the experiment, birds were kept indoors under $12 \mathrm{~h}$ photoperiod (lights on at 08:00) in four flight cages $(1.22 \mathrm{~m} \times 1.22 \mathrm{~m} \times 1.82 \mathrm{~m})$ in groups not exceeding ten individuals per cage. Prior to and throughout the experiment, birds were fed commercial mix for small exotic graminivores (Mała egzotyka, Karma Mix, Bieruń Nowy, Poland) ad libitum, supplemented every other day with fresh greens, hardboiled egg, eggshells and a vitamin and amino acid mixture (Biosupervit, Biofactor, Skierniewice, Poland) added to the drinking water. At least 20 days before respirometry measurements, a miniature thermosensitive PIT tag (BioTherm 13, Biomark, Boise, ID, USA) was implanted intraperitoneally in each bird, which was later used to measure $T_{\mathrm{b}}$ with a remote reader (HPR plus, Biomark, Boise, ID, USA). Prior to implantation, PIT tag readings were calibrated against a precision mercury-in-glass thermometer in a controlled temperature water bath at $T_{\mathrm{a}}$ 's between 30 and $48{ }^{\circ} \mathrm{C}$. All procedures were approved by the Local Committee for Ethics in Animal Research in Bydgoszcz (permit 9/2018 and 26/2018).

During initial acclimation, all birds were kept at constant $T_{\mathrm{a}}$ of $23 \pm 2{ }^{\circ} \mathrm{C}$ with unrestricted access to water. After the first series of respirometry measurements, birds were assigned randomly to four experimental groups. Eighteen birds were acclimated for $\sim 1$ month to a constant $T_{\mathrm{a}}$ of $23{ }^{\circ} \mathrm{C}$, day and night (henceforth $23{ }^{\circ} \mathrm{C}$ ). Of these, eight individuals had access to water ad libitum and ten were water deprived for $6 \mathrm{~h}$, from 11:00 till 17:00 each day. For the $3 \mathrm{~h}$ in the morning and $3 \mathrm{~h}$ in the afternoon, access to water was unlimited. The remaining 18 finches were acclimated to $40{ }^{\circ} \mathrm{C}$ during the $\alpha$-phase and $23{ }^{\circ} \mathrm{C}$ during $\rho$-phase (inactive) (henceforth $40^{\circ} \mathrm{C}$ ). At these $T_{\mathrm{a}}$, s, a group of nine birds was water deprived for $6 \mathrm{~h}$ (as the group at $23{ }^{\circ} \mathrm{C}$ ) and the other nine individuals had access to water $a d l i b$. During the course of acclimation, each week the birds were weighed to $\pm 0.1 \mathrm{~g}$ with an electronic balance (SPU402; Ohaus, USA) to monitor changes in body mass $\left(m_{\mathrm{b}}\right)$. Body mass was also measured before and after each respirometry trial.

\section{Whole-body respirometry}

After initial acclimation and then after acclimation to a different $T_{\mathrm{a}}$ and water regime (henceforth: experimental acclimation), the birds' metabolic rates were measured by indirect calorimetry using an open flow respirometry system (Sable Systems Int., Las Vegas, NV, USA; henceforth: SSI). Measurements were made during the $\alpha$-phase between 08:30 and 16:00 at $T_{\mathrm{a}}$ 's ranging between $\sim 22$ and $44{ }^{\circ} \mathrm{C}$. Air was drawn from outside the building using a compressor pump and stored in a tank, then dried and scrubbed of $\mathrm{CO}_{2}$ with an adsorption dryer (Ecodry K-MT 3, Parker Zander, Charlotte, NC, USA). Next, depending on the size of the group measured simultaneously, the air was continuously pushed through between eight and ten airtight $0.85 \mathrm{~L}$ respirometry chambers constructed of polypropylene containers (HPL 808, Lock\&Lock, Hana Cobi, South Korea) placed in a temperature-controlled cabinet (ST-1200; Pol-Eko-Aparatura, Wodzisław Śląski, Poland). On a given day, each individual was measured at two randomly selected $T_{\mathrm{a}}$ 's for $\sim 3.5 \mathrm{~h}$ at each $T_{a}$ which was sufficient to obtain post-absorptive values at the end of measurements. $T_{\mathrm{a}}$ in respirometry chambers was measured continuously with type-T thermocouples connected to two eight-channel readers (USB 4718; Advantech Europe, Munich, Germany) and was recorded on a PC with WaveScan software (ver. 2.0; Advantech Europe). The walls of each chamber were covered with black adhesive tape and equipped with a perch and metal mesh suspended $\sim 4 \mathrm{~cm}$ above chamber floor in which a $\sim 0.5 \mathrm{~cm}$ layer of mineral oil served as an excreta trap which prevented water evaporation. The main air flow was divided among the chambers, regulated at $\sim 500 \mathrm{ml} \mathrm{min}^{-1}$ and measured upstream with two parallel mass-flow meter systems (Flow-Bar 4 and Flow Bar 8 ). At this flow rate, during measurements at highest $T_{\mathrm{a}}$ 's, water vapor pressure in the chamber did not exceed $2.5 \mathrm{kPa}$ (dewpoint $<21^{\circ} \mathrm{C}$ ). We used two parallel respirometry systems in which three and seven birds could be measured in parallel. In both systems, the excurrent airstream was subsampled at $\sim 150 \mathrm{ml} \mathrm{min}^{-1}$ and pulled through a series of gas analyzers. Two computer-controlled multiplexers (MUX, SSI) automatically switched excurrent airstreams between animal chambers every $5 \mathrm{~min}$. At least once every $20 \mathrm{~min}$, the airstream was switched to a reference airline and the concentration of gases in the incurrent air was measured for $5 \mathrm{~min}$. In the first system, partial pressure of water vapor $\left(P_{\mathrm{H} 2 \mathrm{O}}, \mathrm{kPa}\right)$ in the airstream was measured with an RH-300 water vapor analyzer. Then, fractional concentrations of $\mathrm{CO}_{2}\left(\mathrm{FeCO}_{2}\right)$ and $\mathrm{O}_{2}\left(\mathrm{FeO}_{2}\right)$ in excurrent air stream were measured with a FoxBox-C integrated $\mathrm{CO}_{2}$ and $\mathrm{O}_{2}$ analyzer (SSI). In the second system $P_{\mathrm{H} 2 \mathrm{O}}, \mathrm{FeCO}_{2}$ and $\mathrm{FeO}_{2}$ were analyzed in a sequence with Field Metabolic System analyzer (FMS; SSI). In both systems, air was dried with a Nafion ${ }^{\mathrm{TM}}$ drying tubes (product number 17049, VacuMed, Ventura, CA, USA) embedded in silica gel and then, in a column of magnesium perchlorate (anhydrous, ACS; Alfa Aesar GmbH \& Co KG, Karlsruhe, Germany) before measuring $\mathrm{FeCO}_{2}$ and $\mathrm{FeO}_{2}$. The rate of $\mathrm{O}_{2}$ consumption $\left(\dot{V} \mathrm{O}_{2}\right)$ and $\mathrm{CO}_{2}$ production $\left(\dot{V} \mathrm{CO}_{2}\right.$; both in $\left.\mathrm{ml} \mathrm{min}^{-1}\right)$ were calculated using Eqs. 10.6 and 10.7 of Lighton (2008). The rate of evaporative water loss $\left(\mathrm{mg} \mathrm{H}_{2} \mathrm{O} \mathrm{min}{ }^{-1}\right)$ was calculated using Eq. 10.9 of Lighton (2008) after verification for our system construction. Animal $T_{\mathrm{b}}$ was measured remotely with a PIT tag reader after completing measurement at each $T_{\mathrm{a}}$, when 
animals were still in the chambers. During whole-body and mask respirometry (see below), all elements of the measurement systems were controlled with a PC computer via an analog-to-digital interface (UI2, SSI) and data were acquired using ExpeData software (SSI) at $0.5 \mathrm{~Hz}$.

\section{Mask respirometry}

On completion of whole-body respirometry measurements, and after experimental acclimation of the birds, we analyzed the effect of acclimation on respiratory and cutaneous evaporative heat loss (REHL and CEHL, respectively). To do so, we measured respiratory and cutaneous evaporative water loss at $T_{\mathrm{a}}$ 's of 25 and $40{ }^{\circ} \mathrm{C}$, while the birds wore a mask (Online Resource Fig. 1; Tieleman and Williams 2002). Prior to measurement, birds were trained to wear a mask for a minimum of $30 \mathrm{~min}$, at least 1 day before the trial. During measurement, a bird was placed in a $1.2 \mathrm{~L}$ glass chamber (Ikea $365+$, Ikea, Sweden) covered with a plastic lid lined with aluminum foil (to minimize $\mathrm{H}_{2} \mathrm{O}$ vapor adsorption on the plastic surface). Inside the chamber a wire mesh and a perch were placed $\sim 2.5 \mathrm{~cm}$ above the bottom protected the animal from reaching a $\sim 0.5 \mathrm{~cm}$ layer of mineral oil covering the bottom of the chamber. There was sufficient space for a bird to stand upright on the mesh during measurement. The bird's head was secured with a rubber band in a polyethylene mask (Fig. 4, inset) which covered the whole head (thus REWL values included the $\mathrm{H}_{2} \mathrm{O}$ evaporation from the head skin and eye surfaces). Air flowed into the mask through the space between mask and head. Two small pumps pulled dry air from a column of silica gel into the chamber through a port protruding $\sim 4 \mathrm{~cm}$ deep into the chamber. One pump pulled air through the mask (REWL line) at a constant rate of $500 \mathrm{ml} \mathrm{min}{ }^{-1}$, while the second pump pulled air from the chamber (CEWL line) at $200 \mathrm{ml} \mathrm{min}^{-1}$. We used two separate systems to measure two birds at a time. In one system, air leaving the mask was pulled through an RH-300 (SSI) water vapor analyzer, dried with magnesium perchlorate, then passed through a mass-flowmeter and finally $\mathrm{FeCO}_{2}$ and $\mathrm{FeO}_{2}$ were measured with a FoxBox-C integrated $\mathrm{CO}_{2}$ and $\mathrm{O}_{2}$ analyzer (SSI). Air leaving the chamber was pulled through an RH-300 analyzer, dried with magnesium perchlorate, and the excurrent flow rate was measured with the mass-flowmeter of a subsampling pump (SS-4; SSI). In the second system, excurrent $P_{\mathrm{H} 2 \mathrm{O}}, \mathrm{FeCO}_{2}$ and $\mathrm{FeO}_{2}$ were measured with Field Metabolic System analyzer, while in the chamber line, excurrent $P_{\mathrm{H} 2 \mathrm{O}}$ was measured with RH-300 analyzer. In both lines of the second system, flow rates of air dried with magnesium perchlorate were measured with mass-flowmeters after measuring $P_{\mathrm{H} 2 \mathrm{O}}$. Ambient temperature within chambers was measured continuously with calibrated thermistor probes $\left( \pm 0.1{ }^{\circ} \mathrm{C} ; 803\right.$-PS104R2, Mouser Electronics Inc., Mansfield, TX, USA)) attached to
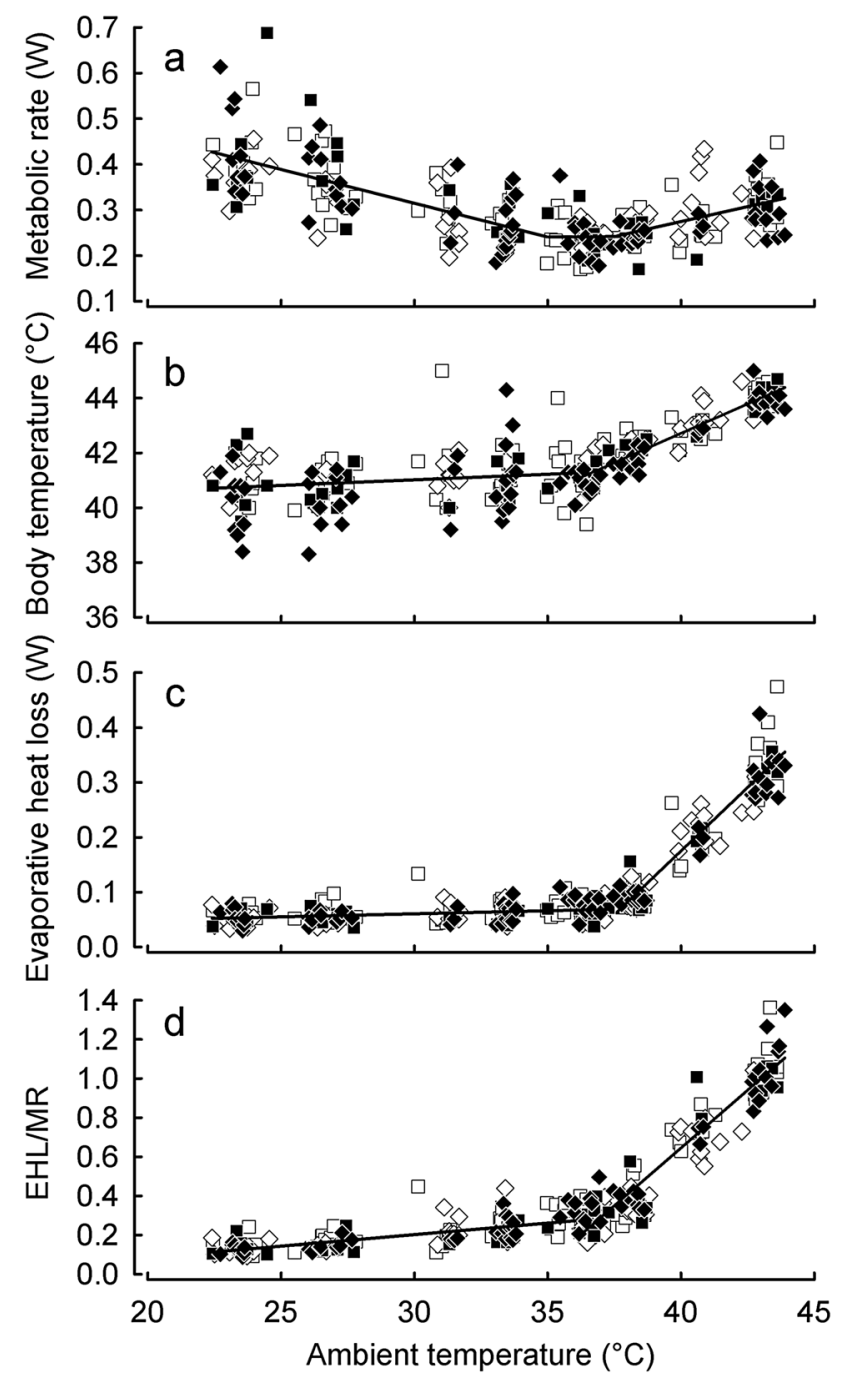

Fig. 1 Metabolic rate (a), body temperature (b), evaporative heat loss (c) and efficiency of evaporative cooling (EHL/MR; d) as function of ambient temperature in zebra finches acclimated to $T_{\mathrm{a}}=23{ }^{\circ} \mathrm{C}$ with unrestricted access to water. Data for initial acclimation are presented together as there was no difference between birds (GAMM: $p>0.1$ for all variables). The solid line is the segmented linear regression model that provided the best fit. Different symbols stand for birds that were later assigned to different experimental acclimation

the lids of respirometry chambers. In both systems, $\dot{V} \mathrm{O}_{2}$ and $\dot{V} \mathrm{CO}_{2}$ were calculated using Eqs. 11.7 and 11.8 of Lighton (2008), while REWL and CEWL were calculated following Tieleman and Williams (2002). Respirometry chambers were placed in a temperature-controlled cabinet (Sanyo Incubator MIR-153, Sanyo Electronic Co. Ltd., Japan). Each measurement lasted $3 \mathrm{~h}$, starting with a $1.5 \mathrm{~h}$ exposure to $25{ }^{\circ} \mathrm{C}$. Then, temperature of the cabinet was set to $40{ }^{\circ} \mathrm{C}$ and the bird remained in the chamber for the following $1.5 \mathrm{~h}$. $T_{\mathrm{a}}$ reached $40{ }^{\circ} \mathrm{C}$ after $\sim 1 \mathrm{~h}$, and the final recording lasted for $\sim 0.5 \mathrm{~h}$. Every $30 \mathrm{~min}$ a computer-controlled multiplexer (MUX; SSI) switched the airstream to a reference air that 
was sampled for $5 \mathrm{~min}$. During that time, a separate pump attached to an outlet port of the solenoid valve of the multiplexer secured continuous flow of air through the mask and the chamber.

Bird $T_{\mathrm{b}}$ was measured at $30 \mathrm{~s}$ intervals and monitored continuously for the duration of the trial with the same system as during whole-body respirometry. In the case of excessive locomotor activity during measurement or excessive hyperthermia, the recording was terminated and the bird was immediately removed from the chamber. No fatalities occurred due to hyperthermia during or after measurements.

\section{Data analysis}

Metabolic rate (MR, W) was calculated assuming a respiratory exchange ratio (RER, $\dot{V} \mathrm{CO}_{2} / \dot{V} \mathrm{O}_{2}$ ) calculated from recorded $\dot{V} \mathrm{CO}_{2}$ and $\dot{V} \mathrm{O}_{2}$ using oxyjoule equivalent calculated after Lighton et al. (1987):

$\mathrm{MR}(\mathrm{W})=\frac{\dot{V} \mathrm{O}_{2}+5.164 \cdot \mathrm{RER}}{60}$

Rate of evaporative heat loss (EHL, W) was calculated from EWL using a latent heat of vaporization of $2.4 \mathrm{~J} \mathrm{mg}^{-1}$ $\mathrm{H}_{2} \mathrm{O}$ (Tracy et al. 2010), and the efficiency of evaporative cooling was calculated as the ratio EHL/MR. Thermal conductance (dry heat transfer coefficient, Tieleman and Williams 1999; $\mathrm{C}, \mathrm{W}{ }^{\circ} \mathrm{C}^{-1} \mathrm{~cm}^{-2}$ ) was calculated based on data collected below lower critical temperature $\left(T_{\mathrm{LC}}\right.$, here: $34.87 \pm 0.65^{\circ} \mathrm{C}$, see "Results" section) following Dawson and Schmidt-Nielsen (1966):

$\mathrm{C}\left(\mathrm{W}^{\circ} \mathrm{C}^{-1} \mathrm{~cm}^{-2}\right)=\frac{\mathrm{MR}-\mathrm{EHL}}{\left(\mathrm{T}_{\mathrm{b}}-\mathrm{T}_{\mathrm{a}}\right) \cdot \mathrm{A}_{\mathrm{s}}}$, where body surface area was calculated following Walsberg and King (1978) as $A_{\mathrm{s}}$ $\left(\mathrm{cm}^{2}\right)=10 m_{\mathrm{b}}^{0.667}$.

In the analysis of the respirometry data, we applied a steady-state approach and collected data were not corrected for instantaneous changes in gas concentrations (c.f. Bartholomew et al. 1981). MR and EHL during whole-body respirometry were calculated using 2 min averages of the lowest values of $\dot{V} \mathrm{O}_{2}$ or concurrent value of EWL recorded at a given $T_{\mathrm{a}}$. For the mask respirometry, we used the average of the most unchanging continuous 5 min recording at a given $T_{\mathrm{a}}$. With that approach, we were able to select the lowest stable recording at $25^{\circ} \mathrm{C}$ and the most stable recording during exposure to $40{ }^{\circ} \mathrm{C}$. In both types of respirometry recordings, we selected $T_{\mathrm{b}}$ for the concurrent MR and EWL calculations.

Since MR, EHL and $T_{\mathrm{b}}$ did not differ between experimental groups after initial acclimation (generalized additive mixed effects models: $p>0.1$, see "Results" section), we determined characteristic points of the Scholander-Irving model (Scholander et al. 1950) for all birds pooled together. After initial visual inspection of the relationships among
MR, EHL and $T_{\mathrm{b}}$, and $T_{\mathrm{a}}$, we used SegReg software (www. waterlog.info/segreg.htm; Oosterbaan et al. 1990) to calculate segmented (piecewise) linear regression equations. In brief, the selection of a best fitting function describing the relationship and the breakpoint is done by maximizing the coefficient of determination and testing the significance of the model (Oosterbaan et al. 1990). Results of these analyses were used to determine $T_{\mathrm{LC}}$, upper critical temperature $\left(T_{\mathrm{UC}}\right)$, the inflection point for EHL and the threshold $T_{\mathrm{a}}$ for hyperthermia; these values were presented \pm S.E.

In the analysis of the effects of experimental acclimation on whole-body MR, EHL, $T_{\mathrm{b}}$ and efficiency of evaporative heat loss (EHL/MR), we used a two-step approach. First, to account for the curvilinear relationship between physiological variables of interest and $T_{\mathrm{a}}$, in the whole range at $T_{\mathrm{a}}$ 's ranging between 22 and $44{ }^{\circ} \mathrm{C}$ (whole range of $T_{\mathrm{a}}$ 's), we fitted generalized additive mixed effects models with the package "mgcv" ver. 1.8-31 (Wood 2006). These analyses allowed us to infer the effects of experimental acclimation on the whole animal response over the whole range of $T_{\mathrm{a}} \mathrm{s}$ to which birds were exposed. In all models, animal ID was set as a random factor to account for the repeated measurements of individuals. Initial models included acclimation (initial or experimental), acclimation regime (henceforth: group), and their interaction as fixed factors, $T_{\mathrm{a}}$ as a smoothed term and $m_{\mathrm{b}}$ as a covariate. Initial maximal models, including all fixed factors and interactions, were simplified by elimination of insignificant terms and the models were selected using information criteria (Crawley 2009). To meet the assumption of normal distribution of residuals (inspected visually), prior to analysis MR, EHL and EHL/MR were square-root transformed. Then, to infer the effect of experimental acclimation on MR, EHL, $T_{\mathrm{b}}$ and EHL/MR at the $T_{\mathrm{a}}$ 's above the birds' upper critical temperature $\left(T_{\mathrm{UC}}=37.47 \pm 0.81^{\circ} \mathrm{C}\right)$, we fitted linear mixed effects models (LME) to the data using "Ime4" package ver. 1.1-23 (Bates et al. 2015). Initial maximal models included acclimation, experimental group, and their interaction as fixed factors, $T_{\mathrm{a}}$ and $m_{\mathrm{b}}$ as a covariates and animal ID as a random factor. Initial maximal models were simplified by stepwise elimination of insignificant terms (Crawley 2009). Prior to the analysis MR, EHL and EHL/MR were square-root transformed to follow the assumtions of linear modelling.

To test whether acclimation resulted in changes in heat loss at $T_{\mathrm{a}}$ 's at which EHL is at its minimum, the thermal conductance was analyzed at $T_{\mathrm{a}}$ 's below lower critical temperature using LME (lme4; Bates et al. 2015). Here, we included acclimation, group and their interaction as fixed factors, $T_{\mathrm{b}}$ and $T_{\mathrm{a}}$ as covariates and animal ID a random factor. Prior to analysis, $\mathrm{C}$ was square-root transformed. Since in all analyses of the whole-body variables we asked for the effect of acclimation, it was retained as a fixed factor in final models. 
Partitioning of evaporative heat loss into cutaneous and respiratory avenues was analyzed by fitting LME to the cutaneous and respiratory EHL, ratio of REHL to CEHL (REHL/ CEHL), and to ratio of CEHL to total EHL (CEHL/TEHL). To meet assumptions of linear modeling (Grafen and Hails 2002), all dependent variables were log-transformed. All initial maximal models included $T_{\mathrm{a}}$ at which measurement was taken $\left(25\right.$ or $\left.40^{\circ} \mathrm{C}\right)$, acclimation group and their interaction as fixed factors. To account for repeated measurements of individuals in all models, animal ID was set as a random factor. In the model for REHL, MR and $m_{\mathrm{b}}$ were included as covariates. The model analyzing CEHL included $T_{\mathrm{b}}$ and $m_{\mathrm{b}}$ as covariates. In the analysis, initial maximal models were simplified by stepwise elimination of insignificant terms (Crawley 2009). Additionally, we analyzed whether $\mathrm{MR}, T_{\mathrm{b}}$ and total (sum of respiratory and cutaneous) EHL differed between the measurements done using the wholebody and mask respirometry. We did so by fitting LME to the data collected by both methods at 25 and $40{ }^{\circ} \mathrm{C}$ with method of measurement and $T_{\mathrm{a}}$ (category) as fixed factors, and animal ID as a random factor. Both MR and EHL were log-transformed prior to analysis.

Repeatability ( $\tau$; Lessells and Boag 1987) of whole-body MR, EHL and $T_{\mathrm{b}}$ as well as CEHL and REHL was estimated for the final models with "rptR" ver. 0.9.22 (Stoffel et al. 2017). We also calculated repeatability of MR and total EHL measured at 25 and $40{ }^{\circ} \mathrm{C}$ using mask and wholebody respirometry. Data were presented as estimated marginal means \pm SE which were calculated using "emmeans" package ver. 1.4.6 (Lenth 2020) and pairwise compared with Tukey's HSD test adjusting for multiple comparisons. Marginal means for the whole range of $T_{\mathrm{a}}$, $s$ were estimated and compared at the center of the $T_{\mathrm{a}}$ range $\left(\sim 34^{\circ} \mathrm{C}\right)$, while for the analyses above the $T_{\mathrm{UC}}$ marginal means were estimated and compared at $T_{\mathrm{a}}=44^{\circ} \mathrm{C}$. All above analyses were done in $\mathrm{R}$ ver. 4.0.0 (R Core Team 2020) Statistical significance was accepted at $p<0.05$.

\section{Results}

After initial acclimation, there was no difference between birds assigned to different acclimation groups in any of the variables analyzed (for the detailed results of the analyses see below). Thermoneutral zone ranged between $T_{\mathrm{LC}}=34.87 \pm 0.65{ }^{\circ} \mathrm{C}$ and $T_{\mathrm{UC}}=37.47 \pm 0.81{ }^{\circ} \mathrm{C}$ (Fig. 1a). Within TNZ, $m_{\mathrm{b}}$-adjusted BMR equaled $0.24 \pm 0.0071 \mathrm{~W}$. Below TNZ metabolic rate increased linearly by $\sim 0.015 \mathrm{~W}{ }^{\circ} \mathrm{C}^{-1}$, while above $T_{\mathrm{UC}}$ it increased at the rate of $\sim 0.013 \mathrm{~W}^{\circ} \mathrm{C}^{-1}$. Up to $T_{\mathrm{a}}=35.94 \pm 0.14{ }^{\circ} \mathrm{C}$ zebra finches regulated their $T_{\mathrm{b}}$ at a relatively constant level of $40.98 \pm 0.09{ }^{\circ} \mathrm{C}$. Above this temperature, $T_{\mathrm{b}}$ increased linearly at the rate of
$0.43{ }^{\circ} \mathrm{C}$ every degree of increase in $T_{\mathrm{a}}$ (Fig. 1b). This increase in $T_{\mathrm{b}}$ preceded an increase in EHL by $\sim 1.5^{\circ} \mathrm{C}$. Below $T_{\mathrm{a}}=37.45 \pm 0.08{ }^{\circ} \mathrm{C}$ EHL was constant and averaged $0.061 \pm 0.0014 \mathrm{~W}$, and above this $T_{\mathrm{a}}$ it increased at a constant rate of $0.045 \mathrm{~W}^{\circ} \mathrm{C}^{-1}$ (Fig. 1c). Finally, below $T_{\mathrm{a}}=36.16 \pm 0.13{ }^{\circ} \mathrm{C}$ EHL accounted for dissipating $\sim 20 \%$ of heat produced, yet above this $T_{\mathrm{a}}$, efficiency of evaporative heat loss (EHL/MR) increased steeply and at highest $T_{\mathrm{a}}$ 's it equaled 1.4 (Fig. 1d).

\section{Whole-animal response to acclimation}

Over the entire range of $T_{\mathrm{a}}$ 's between 22 and $44{ }^{\circ} \mathrm{C}$ metabolic rate of zebra finches from all experimental groups were significantly correlated with $T_{\mathrm{a}}(p<0.001)$ but not with $m_{\mathrm{b}}(p=0.12)$. Changes in MR in response to experimental acclimation depended on the acclimation regime (interaction group $\times$ acclimation: $p<0.001$, Table 1 ). After adjusting for $T_{\mathrm{a}}$ and $m_{\mathrm{b}}$, MR before experimental acclimation did not differ between groups (Tukey's HSD: $0.89<p<1.00)$ and ranged between $0.25 \pm 0.01 \mathrm{~W}$ and $0.26 \pm 0.01 \mathrm{~W}$ (Fig. $2 \mathrm{a}$ ). After adjusting for $m_{\mathrm{b}}$ and $T_{\mathrm{a}}$, mean MR of the group acclimated to $40{ }^{\circ} \mathrm{C}$ with $\mathrm{H}_{2} \mathrm{O}$ available $a d l i b$. decreased by $\sim 10 \%(p<0.0001)$, and water restriction resulted in an additional decrease in MR of $10 \%(p<0.0001)$. At the same time, MR of zebra finches acclimated to $23{ }^{\circ} \mathrm{C}$, under both water regimes, did not differ from $\mathrm{MR}$ recorded after initial acclimation (Tukey's HSD: $p>0.05$ ).

Changes in whole-animal metabolic heat production at $T_{\mathrm{a}}$ 's above the birds' $T_{\mathrm{UC}}$, after adjusting for $m_{\mathrm{b}}$ $(F(1,49.4)=6.72, p<0.05)$ and $T_{\mathrm{a}}(F(1,127.8)=119.77$, $p<0.0001$ ), differed between acclimation regimes (interaction group $\times$ acclimation: $F(3,131.1)=14.42, p<0.0001)$. Water-restricted birds acclimated to $40{ }^{\circ} \mathrm{C}$ decreased MR by $\sim 20 \%$ ( $p<0.0001)$ compared to initial acclimation, while $\mathrm{MR}$ in the birds with unlimited access to $\mathrm{H}_{2} \mathrm{O}$ as well as individuals acclimated to $23{ }^{\circ} \mathrm{C}$ but with restricted $\mathrm{H}_{2} \mathrm{O}$ did not change at $T_{\mathrm{a}}$ 's above $T_{\mathrm{UC}}(p>0.05)$. Finally, MR in zebra finches kept continuously under the initial conditions $\left(23{ }^{\circ} \mathrm{C}\right.$ throughout the day and $\mathrm{H}_{2} \mathrm{O}$ ad lib.) increased at high $T_{\mathrm{a}}$, $\mathrm{s}$ by $\sim 15 \%$ ( $p<0.01$; Fig. 2b). Metabolic rate measured at $T_{\mathrm{a}}$ 's above $T_{\mathrm{UC}}$ differed consistently among individuals when adjusted for $T_{\mathrm{a}}, m_{\mathrm{b}}$, group and acclimation $(\tau=0.39 \pm 0.09$, $p<0.0001)$.

When analyzed over the entire range of $T_{\mathrm{a}}$ 's, variations in body temperature correlated with $T_{\mathrm{a}}(p<0.0001)$ and $m_{\mathrm{b}}$ $(p<0.001$, Table 1) and did not differ between acclimation regimes ( $p=0.82$; Fig. $2 \mathrm{c}$ ). Since $T_{\mathrm{b}}$ did not differ between experimental groups, both before and after experimental acclimation, this term was dropped from the final model. After adjusting for $T_{\mathrm{a}}$ and $m_{\mathrm{b}}$, before experimental acclimation, $T_{\mathrm{b}}$ ranged between $41.03 \pm 0.11^{\circ} \mathrm{C}$ and $41.05 \pm 0.11^{\circ} \mathrm{C}$ (Fig. 2c). 
Table 1 Results of the hypothesis tests for the generalized additive mixed models describing the relationship between ambient temperature $\left(T_{\mathrm{a}}\right.$; smooth term), and zebra finch Taeniopygia guttata response variables (metabolic rate [MR], body temperature $\left[T_{\mathrm{b}}\right]$, evaporative heat loss [EHL] and efficiency of evaporative heat loss [EHL/ MR]) after adjusting for body mass, acclimation (Acl) and acclimation regime (group)

\begin{tabular}{|c|c|c|c|c|c|c|c|}
\hline \multirow[t]{2}{*}{ Response variable } & \multicolumn{3}{|c|}{ Smooth term $\left(T_{\mathrm{a}}\right)$} & \multicolumn{4}{|c|}{ Parametric terms } \\
\hline & e.d.f & $F$ & $p$ & Factor & $d f$ & $F$ & $p$ \\
\hline \multirow[t]{4}{*}{ Sqrt MR } & 6.37 & 117.9 & $<0.0001$ & $m_{\mathrm{b}}$ & 1 & 2.425 & 0.12 \\
\hline & & & & group & 3 & 2.183 & 0.089 \\
\hline & & & & Acl & 1 & 16.020 & $<0.0001$ \\
\hline & & & & group $\times$ Acl & 3 & 12.559 & $<0.0001$ \\
\hline \multirow[t]{2}{*}{$T_{\mathrm{b}}$} & 6.037 & 207.6 & $<0.0001$ & $m_{\mathrm{b}}$ & 1 & 13.307 & 0.00029 \\
\hline & & & & Acl & 1 & 0.052 & 0.82 \\
\hline \multirow[t]{2}{*}{ sqrt EHL } & 7.69 & 700.3 & $<0.0001$ & $m_{\mathrm{b}}$ & 1 & 15.176 & 0.0001 \\
\hline & & & & Acl & 1 & 0.194 & 0.66 \\
\hline \multirow[t]{4}{*}{ sqrt (EHL/MR) } & 7.17 & 713.7 & $<0.0001$ & $m_{\mathrm{b}}$ & 1 & 1.591 & 0.21 \\
\hline & & & & group & 3 & 3.940 & 0.0080 \\
\hline & & & & Acl & 1 & 13.264 & 0.00030 \\
\hline & & & & group $\times$ Acl & 3 & 10.531 & $<0.0001$ \\
\hline
\end{tabular}

Smooth term results show the ANOVA results for the effect of $T_{\mathrm{a}}$, and parametric terms show results for $m_{\mathrm{b}}$ (covariate), group, acclimation and their interaction (fixed factors). Bold font indicates significant relationships $(p<0.05)$

E.d.f. estimated degrees of freedom
After acclimation to initial conditions zebra finches began to develop hyperthermia at $T_{\mathrm{a}}$ 's $>\sim 36{ }^{\circ} \mathrm{C}$ (see above). After acclimation to $40{ }^{\circ} \mathrm{C}$ in birds with unrestricted access to water hyperthermia started to develop at $T_{\mathrm{a}}$ 's $>32.72 \pm 0.37{ }^{\circ} \mathrm{C}$, like in birds acclimated to $23{ }^{\circ} \mathrm{C}$ with restricted water availability $\left(32.92 \pm 0.10{ }^{\circ} \mathrm{C}\right)$. In the remaining groups, we did not observe changes in threshold for initiation of hyperthermia.

At $T_{\mathrm{a}}$ 's above the birds' upper critical temperature, $T_{\mathrm{b}}$ increased with increasing $T_{\mathrm{a}}(F(1,129.0)=799.00$, $p<0.0001$ ) by $\sim 0.4{ }^{\circ} \mathrm{C}$ every $1{ }^{\circ} \mathrm{C}$. When exposed to high $T_{\text {a }}$ 's during metabolic measurements, birds acclimated to constant $T_{\mathrm{a}}=23{ }^{\circ} \mathrm{C}$, both with water $a d$ lib. or restricted, reached $T_{\mathrm{b}}$ 's higher by $\sim 0.4{ }^{\circ} \mathrm{C}$ than during measurements at the same $T_{\mathrm{a}}$, $s$ after initial acclimation (significant interaction group $\times$ acclimation: $F(3$, $131.8)=4.97, p<0.01$, Fig. $2 \mathrm{~d}$ ). When birds acclimated to $40{ }^{\circ} \mathrm{C}$ were measured at high $T_{\mathrm{a}}$ 's, their $T_{\mathrm{b}}$ did not differ between acclimation regimes $(p>0.05$ for both hydric regimes, Fig. 2d). Repeatability of $T_{\mathrm{b}}$ measured during respirometry trials at $T_{\mathrm{a}}$ 's above $T_{\mathrm{UC}}$ equaled $0.29 \pm 0.09(p<0.0001)$.

Evaporative heat loss changed neither in response to different thermal conditions nor $\mathrm{H}_{2} \mathrm{O}$ availability $(p=0.67$, Fig. 2e). Over the whole range of $T_{\mathrm{a}}$ 's, variations in EHL were explained only by $m_{\mathrm{b}}(p<0.001)$ and $T_{\mathrm{a}}(p<0.0001$, Table 1). Above $T_{\mathrm{UC}}$, irrespective of group or acclimation, the rate of evaporative heat loss correlated only with $m_{\mathrm{b}}$ $(F(1,54.9)=9.66, p<0.01)$ and $T_{\mathrm{a}}(F(1,139.3)=1025.30$, $p<0.0001)$. After adjusting for $T_{\mathrm{a}}, m_{\mathrm{b}}$ and acclimation regime EHL differed consistently among individuals $(\tau=0.15 \pm 0.08, p<0.01)$.
Over the entire range of $T_{\mathrm{a}}$, $s$ at which MR was measured, the ratio of EHL to MR was positively related to $T_{\mathrm{a}}(p<0.0001)$, but not to $m_{\mathrm{b}}(p>0.05$, Table 1$)$. The efficiency of evaporative heat loss changed in response to experimental acclimation, and the magnitude of this change differed among acclimation treatments (interaction group $\times$ acclimation: $p<0.0001$, Table 1$)$. After adjusting for $T_{\mathrm{a}}$ and $m_{\mathrm{b}}$ initial values of EHL/MR did not differ among experimental groups $(0.43<p<1.00)$ and ranged between $0.21 \pm 0.01$ and $0.23 \pm 0.01$ (Fig. $2 \mathrm{~g}$ ). After acclimation to $40{ }^{\circ} \mathrm{C}$ with water restriction, efficiency of EHL increased by $38 \%$ compared to initial conditions $(0.29 \pm 0.13$; Tukey's HSD: $p<0.0001)$, while in birds from remaining groups, it did not change (Fig. $2 \mathrm{~g}$ ).

The results were very similar when changes in efficiency of EHL at high $T_{\mathrm{a}}$ 's were analyzed. It increased with increasing $T_{\mathrm{a}}(F(1,135.2)=917.86)$ and did not correlate with $m_{\mathrm{b}}(p>0.05)$. When compared at $44{ }^{\circ} \mathrm{C}$, experimental acclimation resulted in $\sim 20 \%$ increase in EHL/ MR only in water-restricted birds acclimated to $40{ }^{\circ} \mathrm{C}$ during daytime $(p<0.0001)$, while in other groups, the effect of acclimation was not detectable $(p>0.05$; interaction group $\times$ acclimation: $F(3,136.3)=6.93, p<0.001$, Fig. 2h).

Overall, at $T_{\mathrm{a}}$ 's below lower critical temperature, the thermal conductance was affected by $T_{\mathrm{a}}(F(1$, $199.0)=79.78, p<0.0001)$ and $T_{\mathrm{b}}(F(1,217.8)=12.25$, $p<0.001$ ), and its change due to acclimation was affected by acclimation regime (interaction group $\times$ acclimation: $F(3,196.7)=3.10, p<0.05)$. In birds acclimated to $40{ }^{\circ} \mathrm{C}$ conductance decreased with acclimation by $\sim 16 \%$ $(p<0.001)$, irrespective of water availability. At the same 

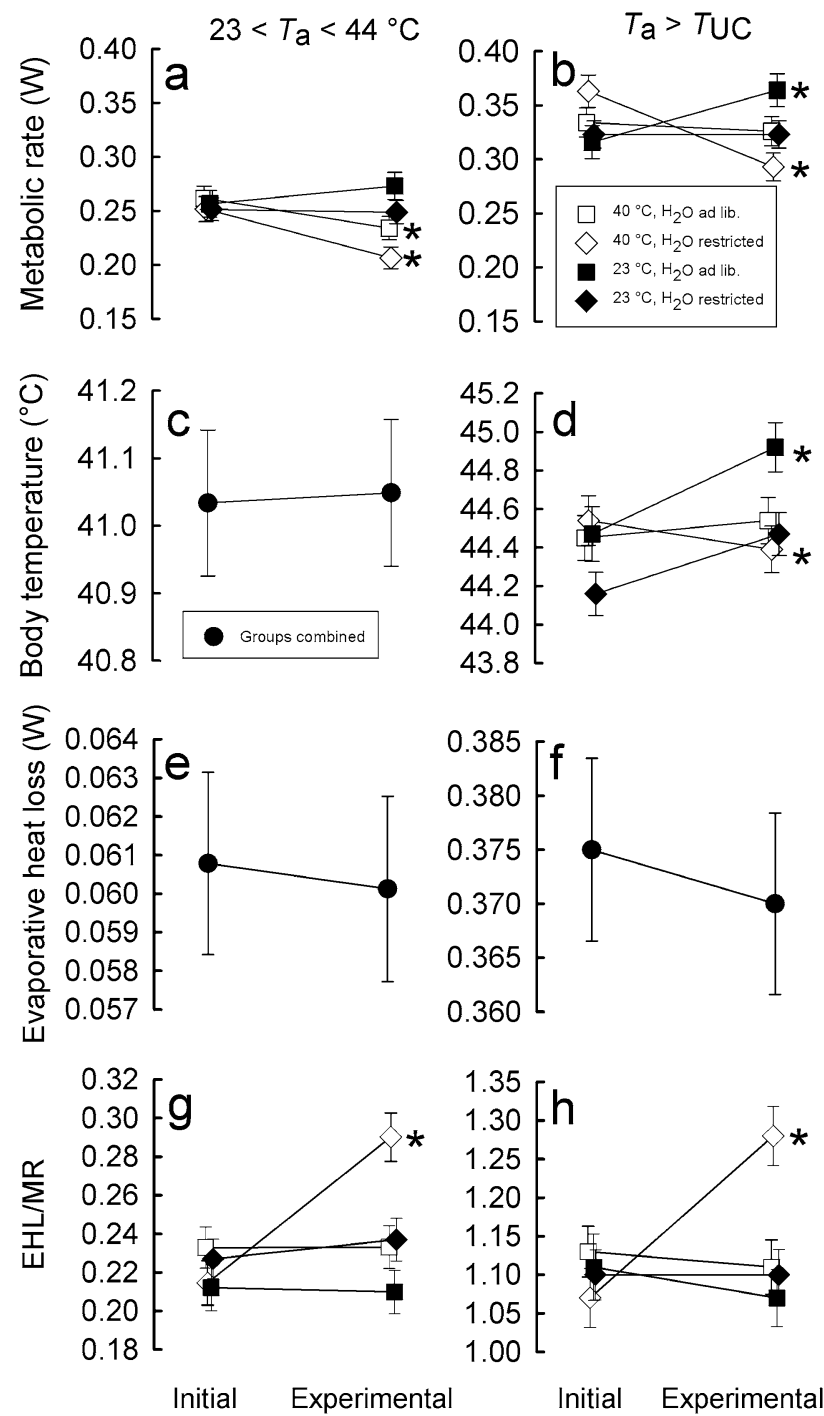

Acclimation

Fig. 2 The effect of experimental acclimation on zebra finch metabolic rate $(\mathrm{W} ; \mathbf{a}, \mathbf{b})$, body temperature $\left({ }^{\circ} \mathrm{C} ; \mathbf{c}, \mathbf{d}\right)$, evaporative heat loss (W; e, f) and efficiency of evaporative heat loss (EHL/MR; g, h) at $T_{\mathrm{a}}$ 's between 23 and $44{ }^{\circ} \mathrm{C}$ and above upper critical temperature $\left(T_{\mathrm{UC}}\right)$. Different symbols (estimated marginal mean $\pm \mathrm{SE}$ ) stand for birds from different experimental groups. $T_{\mathrm{b}}$ (between 23 and $44{ }^{\circ} \mathrm{C}$ ) as well as EHL (at all $T_{\mathrm{a}}$ 's) of birds from different acclimation regimes did not differ $(\mathbf{c}, \mathbf{e}, \mathbf{f})$ and thus groups were pooled together. Marginal means at $T_{\mathrm{a}}>T_{\mathrm{UC}}$ were estimated at $T_{\mathrm{a}}=44{ }^{\circ} \mathrm{C}$. Asterisks indicate significant differences between measurements after initial and experimental acclimation $(p<0.0001)$

time, acclimation to $23{ }^{\circ} \mathrm{C}$ throughout the day did not affect C, irrespective of water availability (Fig. 3).

\section{Partitioning of evaporative heat loss}

After accounting for the effect of ambient temperature (25 and $40^{\circ} \mathrm{C}$ ), the sum of respiratory and cutaneous heat loss measured in birds wearing a mask was $\sim 70 \%$ higher than

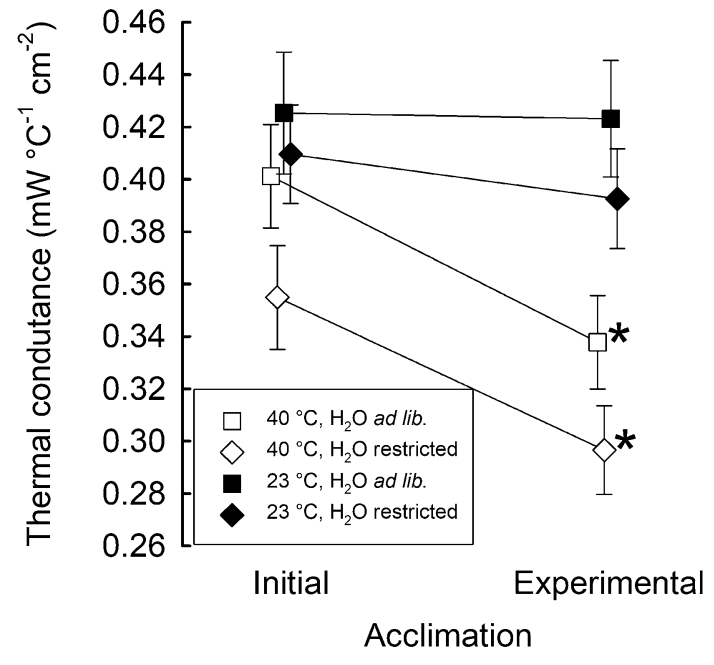

Fig. 3 Thermal conductance $\left(\mathrm{mW}{ }^{\circ} \mathrm{C}^{-1} \mathrm{~cm}^{-2}\right.$; estimated marginal mean $\pm \mathrm{SE}$ ) below lower critical temperature after initial and experimental acclimation. Different symbols stand for zebra finches from different acclimation regimes. Asterisks indicate significant differences within groups $(p<0.05)$

evaporative heat loss measured in unrestrained birds during whole-body measurements (Online Resource Fig. 2a, b). At the same time, metabolic rate measured with a mask system exceeded MR of unrestrained birds by $\sim 33 \%$ (Online Resource Fig. 2c, d), while $T_{\mathrm{b}}$ did not differ during the two measurement methods (Online Resource Fig. 2e, f). Nevertheless, EHL, MR and $T_{\mathrm{b}}$ were repeatable after accounting for different measurement methods and ambient temperature (EHL: $\tau=0.20 \pm 0.10, p<0.05$, MR: $\tau=0.22 \pm 0.10$, $p<0.01$, and $\left.T_{\mathrm{b}}: \tau=0.18 \pm 0.10, p<0.05\right)$.

Respiratory evaporative heat loss was positively correlated with MR $(F(1,48.7)=54.52, p<0.0001)$ and was higher at 40 than at $25{ }^{\circ} \mathrm{C}$, but the magnitude of this difference depended on acclimation regime (interaction group $\times T_{\mathrm{a}}: F(3$, $30.3)=3.08, p<0.05)$. Namely, the difference between 25 and $40{ }^{\circ} \mathrm{C}$ was slightly greater in water-restricted birds under both thermal regimes than in birds having unlimited access to water (Fig. 4a). Individual REHL was highly and significantly repeatable between 25 and $40^{\circ} \mathrm{C}$ when adjusted for $m_{\mathrm{b}}$, MR and acclimation regime $(\tau=0.60 \pm 0.11, p<0.0001)$.

Cutaneous EHL loss did not correlate with $T_{\mathrm{b}}$, MR, $m_{\mathrm{b}}$ or acclimation regime and was higher by $\sim 25 \%$ when birds were exposed to 40 than to $25^{\circ} \mathrm{C}(F(1,33.0)=8.79, p<0.01$, Fig. 4b). After adjusting for $T_{\mathrm{a}}$, CEHL showed consistent among individual differences $(\tau=0.41 \pm 0.14, p<0.01)$.

There was no difference between birds acclimated to different thermal and water regimes in the REHL/CEHL $(p>0.05)$, but this ratio differed between 25 and $40{ }^{\circ} \mathrm{C}$ $(F(1,33.0)=173.56, p<0.0001)$. At $T_{\mathrm{a}}=25{ }^{\circ} \mathrm{C}$, cutaneous evaporative heat loss was over twofold higher than respiratory EHL, while at $T_{\mathrm{a}}=40^{\circ} \mathrm{C}$, the ratio reversed and REHL 

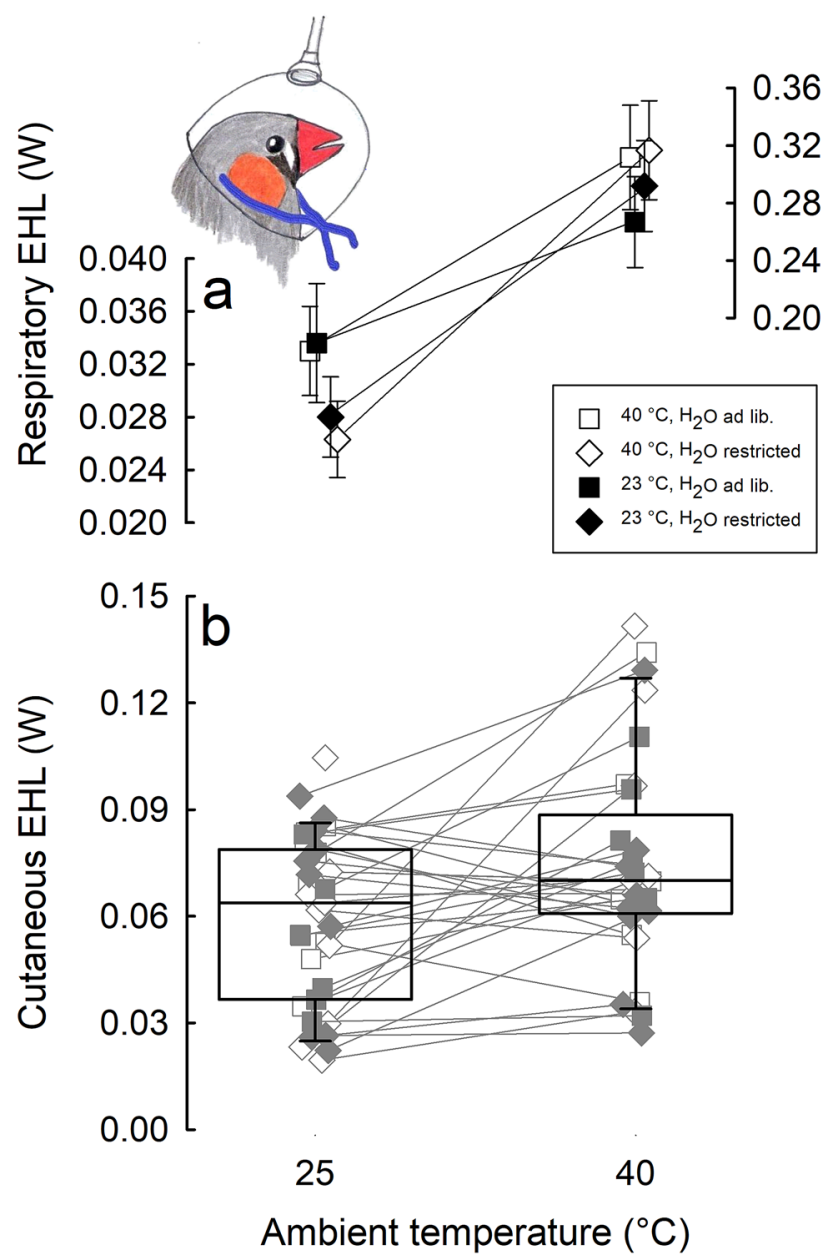

Fig. 4 Respiratory (a) and cutaneous (b) evaporative heat loss (W; estimated marginal mean \pm SE) at 25 and $40{ }^{\circ} \mathrm{C}$ in zebra finches after experimental acclimation. Different symbols stand for birds from different acclimation regimes. Note different scale of axes for parts at 25 and $40{ }^{\circ} \mathrm{C}$ at panel of respiratory EHL (a). Boxes at panel of cutaneous EHL (b) indicate 25th and 75th percentiles, solid line stands for median. Different symbols mark individual birds from different acclimation regimes. Inset: a schematic drawing of zebra finch in the polyethylene mask used for respiratory evaporative water loss measurements. Rubber band securing the mask (blue) was placed under feathers below the occipital region of the skull (color figure online)

exceeded CEHL over threefold (Fig. 5a). As indicated by the analysis of CEHL/TEHL, after adjusting for MR $(F(1$, 55.6) $=5.81, p<0.05$ ), cutaneous avenue at $25^{\circ} \mathrm{C}$ accounted for $61 \%$ of the total $\mathrm{EHL}$, whereas at $40{ }^{\circ} \mathrm{C}$, its contribution decreased to $21 \%(F(1,48.2)=104.74, p<0.0001$, Fig. $5 b)$.

\section{Discussion}

Zebra finches, a small arid zone passerine, increased the efficiency of evaporative heat loss (Fig. 2g, h) and thus precision of $T_{\mathrm{b}}$ regulation (Fig. 2d) in response to prolonged

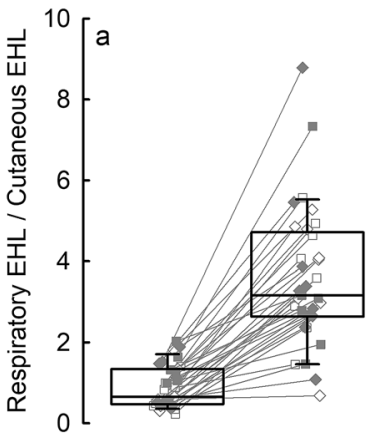

25

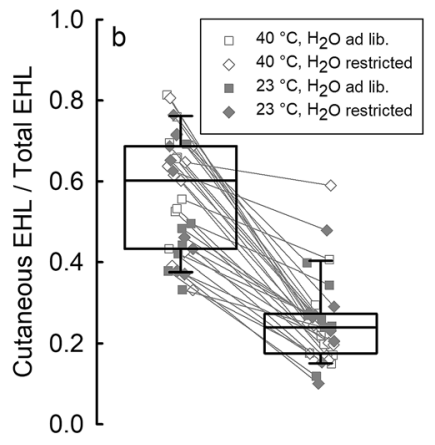

25

40
Ambient temperature $\left({ }^{\circ} \mathrm{C}\right)$

Fig. 5 Respiratory to cutaneous evaporative heat loss (EHL) ratio (a), and contribution of cutaneous EHL to total EHL (b) at $T_{\mathrm{a}}$ of 25 and $40{ }^{\circ} \mathrm{C}$. Boxes indicate 25 th and 75 th percentiles, solid lines stand for median. Different symbols indicate individual birds from different acclimation regimes

exposure to hot and desiccating conditions. Being more effective under harsher conditions, efficiency of EHL was facilitated by a decrease in metabolic heat production (Fig. 2a, b) as the main response in our experimental study. Contrary to our predictions, birds acclimated to high $T_{\mathrm{a}}$ or to water restriction, or both did not decrease total evaporative heat loss (Fig. 2e, f). Yet, irrespective of acclimation temperature, water restriction resulted in lowering of respiratory evaporative heat loss at $T_{\mathrm{a}}$ below thermoneutrality (Fig. 4a). Consistent among-individual differences (repeatability) in metabolic rate, body temperature, and in total, respiratory and cutaneous water loss suggest that these traits may be a target for selection favoring phenotypes most effectively responding to thermally challenging conditions.

\section{Whole-animal response to acclimation}

Before acclimation to experimental conditions, mean zebra finch BMR equaled $0.24 \mathrm{~W}$ which agrees with values reported previously for the species (Cade et al. 1965; Calder 1964) and other similar-sized passerines (McKechnie and Swanson 2010; McKechnie and Wolf 2004a). The differences in MR outside the thermoneutral zone between our results and values reported earlier (Calder 1964; Cooper et al. 2020b) may result from the differences in time of the day when MR was measured. Namely, our birds were measured during $\alpha$-phase, Cooper et al. (2020b) measured birds during $\rho$-phase, and birds of Calder (1964) were kept under an inverted light-dark cycle. In passerines, heat loss considerably differs between $\alpha$ and $\rho$-phases, being $~ 50 \%$ lower in $\rho$-phase (Aschoff 1981). Lower critical temperature recorded in present study corresponds well to the value reported by Cade et al. (1965), but is higher by $\sim 6^{\circ} \mathrm{C}$ than that reported by Calder (1964), while upper critical temperature $\left(T_{\mathrm{UC}}\right)$ 
is $\sim 2.5^{\circ} \mathrm{C}$ lower than reported by Calder (1964) and Cade et al. (1965). The most plausible explanation for this difference was $\sim 20 \%$ lower MR of birds at $T_{\mathrm{a}}$ 's between 42 and $44{ }^{\circ} \mathrm{C}$ in our study than in Calder (1964).

Our results concur with most recent studies on thermoregulatory responses of zebra finches to simulated and natural heat waves (Cooper et al. 2020a, b). The same shape of relationship between MR and $T_{\mathrm{a}}$ recorded after initial and experimental acclimation (Fig. 1) suggests no biologically meaningful change in the lower and upper critical temperatures in response to acclimation to heat, as it was suggested by Cooper et al. (2020a). The main response of zebra finches to $40{ }^{\circ} \mathrm{C}$ during daytime was the overall decrease of heat production over the entire range of ambient temperatures, which was further augmented by water restriction (Fig. 2a, b). Flexible adjustment of MR to prevailing thermal conditions reflects a common reaction of small endothermic homeotherms to changes in energy demands (for reviews see: Bicudo et al. 2010; McKechnie 2008; Piersma and Van Gils 2011). Acclimation to $T_{\mathrm{a}}$ 's below thermoneutrality lead to increased BMR (Barcelo et al. 2017; Vezina et al. 2017), while acclimation to $T_{\mathrm{a}}$ ' $\mathrm{s}>T_{\mathrm{LC}}$ resulted in MR decrease both in birds (Harrison and Biellier 1969; McKechnie et al. 2007; Noakes and McKechnie 2020; Tieleman et al. 2003; Vezina et al. 2006; Williams and Tieleman 2005, 2000) and in mammals (Boratyński et al. 2016b; Chaffee and Roberts 1971; Nespolo et al. 2001). However, at $T_{\mathrm{a}}$ 's above thermoneutrality, only zebra finches acclimated to high $T_{\mathrm{a}}$ and restricted water availability reduced metabolic heat production. This suggests that the overall reduction of MR in the groups acclimated to high diurnal $T_{\mathrm{a}}$ (Fig. 2a) was due to reduced metabolism at $T_{\mathrm{a}}$ 's below their $T_{\mathrm{UC}}$. Our results suggest that heat-acclimated birds exposed to $T_{\mathrm{a}}$ 's below their $T_{\mathrm{UC}}$ may conserve energy, reduce the use of energy reserves and even accumulate it when in positive energy balance. Eventually, when exposed to high $T_{\mathrm{a}}$ 's with limited water availability, birds could use these body reserves as a source of water produced in fat and protein catabolism. Support for this mechanism comes from studies by Gerson and Guglielmo (2011), Rutkowska et al. (2016) and McCue et al. (2017) who showed that both birds and mammals may rely on fat and protein catabolism to sustain water needs during dehydration, fasting and sustained exercise during migration flight.

Overall, regulation of body temperature in zebra finches below their $T_{\mathrm{LC}}$ was not affected by acclimation regimes. At $T_{\mathrm{a}}>36{ }^{\circ} \mathrm{C}, T_{\mathrm{b}}$ increased linearly together with linear increase of evaporative heat loss and the efficiency of evaporative heat loss (EHL/MR), as in other Australian and Southern African passerines of similar $m_{\mathrm{b}}$ (Freeman et al. 2020; McKechnie et al. 2017; Whitfield et al. 2015). Conversely, Cooper et al. (2020b) found that acclimation of zebra finches to experimental conditions mimicking heat-wave did not increase their $T_{\mathrm{b}}$ as it was recorded under natural conditions (Cooper et al. 2020a). But they measured $T_{\mathrm{b}}$ only at 30 and $40{ }^{\circ} \mathrm{C}$. In our study, after initial acclimation, all birds started to develop hyperthermia at $T_{\mathrm{a}}$ of $\sim 36^{\circ} \mathrm{C}$, i.e. $\sim 1.5^{\circ} \mathrm{C}$ lower than their $T_{\mathrm{UC}}$ and lower than temperature at which evaporative heat loss started to increase (Fig. 1). Regulated hyperthermia is one of the main mechanisms allowing birds to minimize water loss at high $T_{\mathrm{a}}$ 's (Calder and King 1974; Gerson et al. 2019; Tieleman and Williams 1999). One might expect that acclimation to high $T_{\mathrm{a}}$ and water restriction would lead to a shift of the hyperthermia threshold to lower $T_{\mathrm{a}}$ 's. This was partially true. Only birds acclimated to $40{ }^{\circ} \mathrm{C}$ with ad libitum access to water, and birds acclimated to $23{ }^{\circ} \mathrm{C}$ with water restriction, initiated hyperthermia at $T_{\mathrm{a}}$ 's lower by $\sim 3{ }^{\circ} \mathrm{C}$ than before experimental acclimation. Despite these differences, we found a significant effect of acclimation regime on $T_{\mathrm{b}}$ at $T_{\mathrm{a}}$, s above the birds' $T_{\mathrm{UC}}$ (Fig. 2d). Birds acclimated to $40{ }^{\circ} \mathrm{C}$ irrespective of water availability regulated $T_{\mathrm{b}}$ at the same level as before acclimation, while zebra finches acclimated to $23^{\circ} \mathrm{C}$ increased it significantly. On the one hand, this may indicate that heat-acclimated individuals dissipated heat more effectively. This might be true for birds acclimated to heat and restricted water (Fig. 2g, h). On the other hand, thermal conductance in birds acclimated to $40{ }^{\circ} \mathrm{C}$ decreased by $\sim 16 \%$, irrespective of water regime, while in birds acclimated to $23{ }^{\circ} \mathrm{C}$, it did not change (Fig. 3). We also cannot exclude the possibility of additional changes in heat transfer resulting from e.g. vasomotor changes during exposure to high $T_{\mathrm{a}}$ 's in hot acclimated birds. As suggested by Dawson and Schmidt-Nielsen (1966), at high $T_{\mathrm{a}}$ 's, endothermic animals can prevent heat flow from the environment to the body by decreasing thermal conductance. Also, summer acclimation may result in decreased dry heat transfer at ambient temperatures exceeding $T_{\mathrm{b}}$ (Tieleman et al. 2002b; but see: Tieleman and Williams 1999) possibly due to vasoconstriction of the peripheral blood vessels. A few studies of desert passerines show contradictory results. On one hand, whitebrowed sparrow-weavers Plocepasser mahali acclimated to day-time temperatures between 30 and $42{ }^{\circ} \mathrm{C}$ increased the threshold for hyperthermia in response to acclimation to high $T_{\mathrm{a}}$ (Noakes and McKechnie 2019). At the same time, birds acclimated to $40{ }^{\circ} \mathrm{C}$ maintained lower $T_{\mathrm{b}}$ than those acclimated to $30^{\circ} \mathrm{C}$ (Noakes and McKechnie 2019). On the other hand, another study found no effect of high $T_{\mathrm{a}}$ on $T_{\mathrm{b}}$ (Oswald et al. 2018) and reported that acclimatization to hot summers resulted in lower $T_{\mathrm{b}}$ when birds were exposed to $T_{\mathrm{a}}$ 's $>40{ }^{\circ} \mathrm{C}$ (Noakes et al. 2016). Yet, both Noakes et al. (2016) and Oswald et al. (2018) found that acclimatization to summer was accompanied by significant increases in EWL as well as in the efficiency of evaporative cooling. Noakes et al. (2016) reported that maintenance of lower $T_{\mathrm{b}}$ at high $T_{\mathrm{a}}$ 's by white-browed sparrow-weavers in summer correlated 
with seasonally lower MR, which was not observed in Cape rockjumpers Chaetops frenatus (Oswald et al. 2018). Comparison of our results with the above studies shows that acclimation or acclimatization to hot and desiccating conditions in desert adapted species leads to improved thermoregulation at high $T_{\mathrm{a}}$ 's. This seems to be achieved by changes in physiological mechanisms improving the efficiency of evaporative cooling, both by changes in evaporative heat loss or metabolic heat production or both, which additionally may be facilitated by adjustments in thermal conductance. However, it seems that all of these adjustments need to be accompanied by high tolerance of dehydration as is often characteristic for desert-adapted species (Maclean 1996). Since metabolic water production is directly related to metabolic heat production, lower metabolic rate in hot acclimated and water-restricted birds should result in lower rate of water release. Eventually, lack of changes in whole-body EHL in zebra finches or increased evaporative water loss in other species would lead to inevitably higher water loss. Without evolving mechanism of increased dehydration tolerance, the observed responses to acclimation or acclimatization to hot and desiccating conditions would need to be selected out by natural selection.

\section{Partitioning of evaporative heat loss}

In this study, we also asked whether prolonged exposure to high temperature and water restriction affected partitioning of evaporative heat loss between respiratory and cutaneous avenues. The sum of respiratory and cutaneous EHL measured with mask respirometry considerably excided EHL measured with whole-body approach (see "Results" section and Online Resource Fig. 2). This difference may result from two reasons. We have no doubt that stress resulting from immobilization and wearing a mask lead to increased metabolic rate (and thus increased respiration rate; however, it was rather not associated with stress hyperthermia or emotional fever since $T_{\mathrm{b}}$ did not differ between the two measurement methods) compared to unrestrained individuals leading to greater water loss from the respiratory evaporative surfaces. Second, the high flowrate of air through the mask could result in faster depletion of humid air leading to greater heat loss in finches wearing a mask (c.f. Gerson et al. 2014). Lack of differences in $T_{\mathrm{b}}$ of masked and unrestrained birds supports this possibility. Nevertheless, the results obtained with both methods, although quantitatively different, were repeatable allowing us to conclude about the effect of experimental acclimation on evaporative heat loss partitioning in zebra finches.

Since water deprivation was found to affect both total (Calder 1964; Greenwald et al. 1967) and cutaneous evaporation (Arad et al. 1987), we expected that acclimation to water restriction would result in lower cutaneous evaporative heat loss than in birds having unlimited access to water. Similarly, acclimation to desiccating conditions in house sparrows Passer domesticus resulted in reduction of cutaneous water loss (Muñoz-Garcia et al. 2008). However, this was not the case in present study. Overall, changes in EHL partitioning with $T_{\mathrm{a}}$ (Figs. 4 and 5) agree with patterns observed in other passerine species (Tieleman and Williams 2002; Wolf and Walsberg 1996). Interestingly, in water-restricted birds acclimated to both thermal regimes, we observed a slightly lower respiratory EHL at $25{ }^{\circ} \mathrm{C}$ than in birds having unrestricted access to water (Fig. 4a). Lower REHL at $25{ }^{\circ} \mathrm{C}$ might have provided water savings necessary for thermoregulation at high $T_{\mathrm{a}}$ 's. The underlying mechanism may be related to differences in blood flow to the walls of respiratory tract or changes in counter-current heat exchange in cranial circulation (Bernstein 1982). Although CEHL did not contribute much to total evaporative heat loss at $40{ }^{\circ} \mathrm{C}$ (Fig. 5), our observations suggest that it may be of great importance for birds exposed to high $T_{\mathrm{a}}$ 's. On several occasions, we observed that during measurements at $40{ }^{\circ} \mathrm{C}$ CEHL increased periodically by more than $50 \%$ and this change was accompanied by subsequent decrease of $T_{\mathrm{b}}$. Examination of the heat loss and metabolic heat production indicated that this change in CEHL resulted in increase of TEHL to a level comparable to metabolic heat production (Fig. 6). Increase in CEHL was also accompanied by wing drooping which exposed underwing apteria. Unfortunately, these were only accidental observations which did not permit formal analysis of this behavior. Yet, it is well documented that wing drooping is one of the most common behaviors in hot exposed birds (Pattinson et al. 2020; Smit et al. 2016) and together with our observations may suggest that it may be responsible for an important change in total heat loss, together with gular fluttering and panting at a resonant frequencies of respiratory system (c.f. McKechnie and Wolf 2019).

\section{Conclusions}

Zebra finches exposed to hot and desiccating conditions flexibly adjusted metabolic heat production which increased the efficiency of evaporative heat loss and facilitated regulation of body temperature. Such phenotypic flexibility may be crucial in response to changes in environmental conditions, especially in the face of present and predicted climate change (present study; Cooper et al. 2020b; Noakes and McKechnie 2019; Noakes et al. 2016; Oswald et al. 2018; Tieleman et al. 2002b, 2002a; Williams and Tieleman 2000, 2002). Possibly, this phenotypic flexibility may also undergo seasonal changes as it was shown in mammals (Boratyński et al. 2016a, 2017b). Also, since thermal history may affect flexibility of energy metabolism (Barcelo et al. 2009), we 


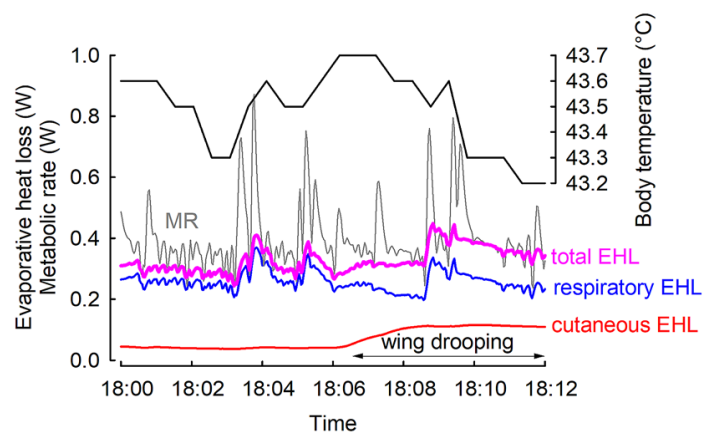

Fig. 6 Representative recording of body temperature (black line), metabolic rate (MR, grey line), total evaporative heat loss (total EHL, REHL + CEHL; pink line), respiratory evaporative heat loss (blue line), and cutaneous evaporative heat loss (red line) in one zebra finch measured at $T_{\mathrm{a}}=40^{\circ} \mathrm{C}$. Black arrows indicate the time of wing drooping (color figure online)

cannot exclude that acclimation to high $T_{\mathrm{a}}$ 's in summer may additionally facilitate flexible adjustments of thermoregulatory traits. This would be of great importance especially since probability of extreme weather events is increasing with increasing mean summer $T_{\mathrm{a}}$ (Conradie et al. 2019; Harris et al. 2018). However, even though potential benefits of flexible adjustments in physiology improve heat tolerance in birds, both theoretical predictions as well as empirical data show population declines in many species living in hot and dry regions of the globe (Albright et al. 2017; Conradie et al. 2019, 2020; McKechnie and Wolf 2010; Riddell et al. 2019). Significant repeatability of whole animal metabolic rate, total evaporative heat loss, as well as cutaneous and respiratory heat loss suggest that these traits may be a subject to natural selection, provided that they are heritable (Boratyński et al. 2017a; Dohm 2002; Rønning et al. 2005, 2007). Current and future selection pressure may favour individuals with the greatest potential for phenotypic changes in heat tolerance (c.f. Cooper et al. 2020b; McKechnie et al. 2012) resulting in greater tolerance of short-term extreme weather events.

Acknowledgements This study was supported by National Science Center Grant 2017/25/B/NZ8/00541 to MSW. We would like to thank Ulf Bauchinger, Berry Pinshow and Anna Przybylska-Piech for discussions and comments on the early version of the manuscript. We also thank anonymous reviewer for constructive comments on the manuscript. James Turner and Russell V. Lenth helped with statistical analysis in R. We would like to thank Emily Cornelius Ruhs and François Vézina for inviting us to present results from this article during the symposium "Hitting a wall: the pace of flexible adjustments to acute environmental change" at the 10th International Congress of Comparative Physiology and Biochemistry that was held in Ottawa (ON, Canada) in August 2019.

Author contributions MSW and MJ designed the experiment. MSW, $\mathrm{AK}, \mathrm{RCC}$ and MJ done the experiment and collected the data. MSW analyzed the data with help of RCC. MSW wrote the manuscript. MJ and RCC provided review and editing. MSW acquired funding. All authors read and approved the final manuscript.

Funding This study was supported by National Science Center Grant 2017/25/B/NZ8/00541.

Availability of data and material The datasets generated during and/or analysed during the current study are available from the corresponding author on a reasonable request.

Code availability Code will be available upon request to the authors.

\section{Compliance with ethical standards}

Conflict of interest The authors declare that they have no conflict of interest.

Ethics approval All procedures were approved by the Local Committee for Ethics in Animal Research in Bydgoszcz (permits 9/2018 and 26/2018).

Consent to participate Not applicable.

Consent for publication All authors agreed to be listed and approved the manuscript and this submission.

Open Access This article is licensed under a Creative Commons Attribution 4.0 International License, which permits use, sharing, adaptation, distribution and reproduction in any medium or format, as long as you give appropriate credit to the original author(s) and the source, provide a link to the Creative Commons licence, and indicate if changes were made. The images or other third party material in this article are included in the article's Creative Commons licence, unless indicated otherwise in a credit line to the material. If material is not included in the article's Creative Commons licence and your intended use is not permitted by statutory regulation or exceeds the permitted use, you will need to obtain permission directly from the copyright holder. To view a copy of this licence, visit http://creativecommons.org/licenses/by/4.0/.

\section{References}

Albright TP, Mutiibwa D, Gerson AR, Smith EK, Talbot WA, O'Neill JJ, McKechnie AE, Wolf BO (2017) Mapping evaporative water loss in desert passerines reveals an expanding threat of lethal dehydration. Proc Natl Acad Sci USA 114(9):2283-2288. https ://doi.org/10.1073/pnas.1613625114

Arad Z, Gavrieli-Levin I, Eylath U, Marder J (1987) Effect of dehydration on cutaneous water evaporation in heat-exposed pigeons (Columba livia). Physiol Zool 60(6):623-630. https://doi. org/10.1086/physzool.60.6.30159978

Aschoff $\mathbf{J}$ (1981) Thermal conductance in mammals and birds: Its dependence on body size and crcadian phase. Comp Biochem Physiol A Physiol 69(4):611-619. https://doi.org/10.1016/03009629(81)90145-6

Bakken GS (1992) Measurement and application of operative and standard operative temperatures in ecology. Am Zool 32(2):194-216

Barcelo G, Love OP, Vezina F (2017) Uncoupling basal and summit metabolic rates in white-throated sparrows: digestive demand drives maintenance costs, but changes in muscle mass are not needed to improve thermogenic capacity. Physiol Biochem Zool PBZ 90(2):153-165. https://doi.org/10.1086/689290 
Barcelo G, Salinas J, Cavieres G, Canals M, Sabat P (2009) Thermal history can affect the short-term thermal acclimation of basal metabolic rate in the passerine Zonotrichia capensis. J Therm Biol 34(8):415-419. https://doi.org/10.1016/j.jtherbio.2009.06.008

Bartholomew GA, Vleck D, Vleck CM (1981) Instantaneous measurements of oxygen-consumption during pre-flight warm-up and post-flight cooling in sphingid and saturniid moths. J Exp Biol 90(Feb):17-32

Bates D, Mächler M, Bolker B, Walker S (2015) Fitting linear mixedeffects models Usinglme4. J Stat Softw. https://doi.org/10.18637 /jss.v067.i01

Bernstein MH (1982) Temperature regulation in exercising birds. In: Taylor CR, Johansen K, Bolis L (eds) A companion to animal physiology. Cambridge University Press, Cambridge, pp 189-197

Bicudo JEP, Buttemer WA, Chappell MA (2010) Ecological and environmental physiology of birds. Oxford University Press, Oxford

Boratyński JS, Jefimow M, Wojciechowski MS (2016a) Phenotypic flexibility of energetics in acclimated Siberian hamsters has a narrower scope in winter than in summer. J Comp Physiol [B] 186(3):387-402. https://doi.org/10.1007/s00360-016-0959-3

Boratyński JS, Jefimow M, Wojciechowski MS (2016b) Phenotypic flexibility of energetics in acclimated Siberian hamsters has a narrower scope in winter than in summer. J Comp Physiol B. https:// doi.org/10.1007/s00360-016-0959-3

Boratyński JS, Jefimow M, Wojciechowski MS (2017a) Individual differences in the phenotypic flexibility of basal metabolic rate in siberian hamsters are consistent on short- and long-term timescales. Physiol Biochem Zool PBZ 90(2):139-152. https://doi. org/10.1086/689870

Boratyński JS, Jefimow M, Wojciechowski MS (2017b) Melatonin attenuates phenotypic flexibility of energy metabolism in a photoresponsive mammal, the Siberian hamster. J Exp Biol 220(17):3154-3161. https://doi.org/10.1242/jeb.159517

Cade TJ, Tobin CA, Gold A (1965) Water economy and metabolism of two estrildine finches. Physiol Zool 38(1):9-33. https://doi. org/10.1086/physzool.38.1.30152342

Calder WA (1964) Gaseous metabolism and water relations of the zebra finch Taeniopygia castanotis. Physiol Zool 37(4):400-413

Calder WA, King JR (1974) Thermal and caloric relations of birds. In: Farner DS, King JR (eds) Avian biology, vol IV. Academic Press, New York, pp 259-413

Chaffee RRJ, Roberts JC (1971) Temperature acclimation in birds and mammals. Annu Rev Physiol 33(1):155-202. https://doi. org/10.1146/annurev.ph.33.030171.001103

Conradie SR, Woodborne SM, Cunningham SJ, McKechnie AE (2019) Chronic, sublethal effects of high temperatures will cause severe declines in southern African arid-zone birds during the 21st century. Proc Natl Acad Sci USA. https://doi.org/10.1073/pnas.18213 12116

Conradie SR, Woodborne SM, Wolf BO, Pessato A, Mariette MM, McKechnie AE (2020) Avian mortality risk during heat waves will increase greatly in arid Australia during the 21st century. Conserv Physiol 8 (1):coaa048. https://doi.org/10.1093/conphys/ coaa048

Cooper CE, Hurley LL, Deviche P, Griffith SC (2020) Physiological responses of wild zebra finches (Taeniopygia guttata) to heatwaves. J Exp Biol. https://doi.org/10.1242/jeb.225524

Cooper CE, Hurley LL, Griffith SC (2020) Effect of acute exposure to high ambient temperature on the thermal, metabolic and hygric physiology of a small desert bird. Comp Biochem Physiol A Mol Integr Physiol. https://doi.org/10.1016/j.cbpa.2020.110684

Crawley MJ (2009) The R book. Wiley, Chichester

Dawson T, Schmidt-Nielsen K (1966) Effect of thermal conductance on water economy in the antelope jack rabbit, Lepus alleni. J Cell Physiol 67(3):463-471. https://doi.org/10.1002/jcp.1040670311
Dawson WR (2003) Plasticity in avian responses to thermal challenges - an essay in honor of Jacob Marder. Israel J Zool 49(2-3):95-109

Dohm MR (2002) Repeatability estimates do not always set an upper limit to heritability. Funct Ecol 16(2):273-280. https://doi.org/10 .1046/j.1365-2435.2002.00621.x

Freeman MT, Czenze ZJ, Schoeman K, McKechnie AE (2020) Extreme hyperthermia tolerance in the world's most abundant wild bird. Sci Rep 10(1):13098. https://doi.org/10.1038/s41598-020-69997 $-7$

Gerson AR, Guglielmo CG (2011) Flight at low ambient humidity increases protein catabolism in migratory birds. Science 333(6048):1434-1436. https://doi.org/10.1126/science.1210449

Gerson AR, McKechnie AE, Smit B, Whitfield MC, Smith EK, Talbot WA, McWhorter TJ, Wolf BO (2019) The functional significance of facultative hyperthermia varies with body size and phylogeny in birds. Funct Ecol. https://doi.org/10.1111/1365-2435.13274

Gerson AR, Smith EK, Smit B, McKechnie AE, Wolf BO (2014) The impact of humidity on evaporative cooling in small desert birds exposed to high air temperatures. Physiol Biochem Zool PBZ 87(6):782-795. https://doi.org/10.1086/678956

Grafen A, Hails R (2002) Modern statistics for life sciences. Oxford University Press, New York

Greenwald L, Stone WB, Cade TJ (1967) Physiological adjustments of the budgerygah (Melopsittacus undulatus) to dehydrating conditions. Comp Biochem Physiol 22(1):91-100. https://doi. org/10.1016/0010-406X(67)90170-3

Harris RMB, Beaumont LJ, Vance TR, Tozer CR, Remenyi TA, Perkins-Kirkpatrick SE, Mitchell PJ, Nicotra AB, McGregor S, Andrew NR, Letnic M, Kearney MR, Wernberg T, Hutley LB, Chambers LE, Fletcher MS, Keatley MR, Woodward CA, Williamson G, Duke NC, Bowman DMJS (2018) Biological responses to the press and pulse of climate trends and extreme events. Nat Clim Change 8(7):579-587. https://doi.org/10.1038/ s41558-018-0187-9

Harrison PC, Biellier HV (1969) Physiological response of domestic fowl to abrupt changes of ambient air temperature. Poult Sci 48(3):1034-1045. https://doi.org/10.3382/ps.0481034

IPCC (2014) Climate change 2014: synthesis report. Contribution of working groups I, II and III to the fifth assessment report of the intergovernmental panel on climate change. IPCC, Geneva, Switzerland

Jenni-Eiermann S, Jenni L (2012) Fasting in birds: general patterns and the special case of endurance flight. In: McCue MD (ed) Comparative physiology of fasting, starvation, and food limitation. Springer, Berlin Heidelberg, pp 171-192. https://doi. org/10.1007/978-3-642-29056-5_11

Lenth R (2020) Emmeans: estimated marginal means, aka least-squares means. R package version 1.4.6. https://CRAN.R-project.org/ package $=$ emmeans. Accessed May 2020

Lessells CM, Boag PT (1987) Unrepeatable repeatabilities: a common mistake. Auk 104(1):116-121. https://doi.org/10.2307/4087240

Lighton JRB (2008) Measuring metabolic rates: a manual for scientists. Oxford University Press Inc, New York

Lighton JRB, Bartholomew GA, Feener DH (1987) Energetics of locomotion and load carriage and a model of the energy cost of foraging in the leaf-cutting ant Atta colombica Guer. Physiol Zool 60:524-537

Maclean GL (1996) Ecophysiology of desert birds. Springer, Berlin

Marder J (1983) Cutaneous water evaporation-II. Survival of birds under extreme thermal stress. Comp Biochem Physiol A Comp Physiol 75 (3):433-439

Marder J, Arieli Y (1988) Heat-balance of acclimated pigeons (Columba-Livia) exposed to temperatures up to $60{ }^{\circ} \mathrm{C} T_{\mathrm{a}}$. Comp Biochem Physiol Physiol 91(1):165-170 
Marder J, Gavrieli-Levin I (1987) The heat-acclimated pigeon: an ideal physiological model for a desert bird. J Appl Physiol 62(3):952-958

McCue MD, Sandoval J, Beltran J, Gerson AR (2017) Dehydration causes increased reliance on protein oxidation in mice: a test of the protein-for-water hypothesis in a mammal. Physiol Biochem Zool PBZ 90(3):359-369. https://doi.org/10.1086/690912

McKechnie AE (2008) Phenotypic flexibility in basal metabolic rate and the changing view of avian physiological diversity: a review. $\mathrm{J}$ Comp Physiol [B] 178(3):235-247. https://doi.org/10.1007/s0036 0-007-0218-8

McKechnie AE, Chetty K, Lovegrove BG (2007) Phenotypic flexibility in the basal metabolic rate of laughing doves: responses to shortterm thermal acclimation. J Exp Biol 210(Pt 1):97-106. https:// doi.org/10.1242/jeb.02615

McKechnie AE, Gerson AR, McWhorter TJ, Smith EK, Talbot WA, Wolf BO (2017) Avian thermoregulation in the heat: evaporative cooling in five Australian passerines reveals within-order biogeographic variation in heat tolerance. J Exp Biol 220(Pt 13):24362444. https://doi.org/10.1242/jeb.155507

McKechnie AE, Hockey PAR, Wolf BO (2012) Feeling the heat: Australian landbirds and climate change. Emu 112(2):i-vii. https:// doi.org/10.1071/MUv112n2 ED

McKechnie AE, Swanson DL (2010) Sources and significance of variation in basal, summit and maximal metabolic rates in birds. Curr Zool 56(6):741-758

McKechnie AE, Wolf BO (2004a) The allometry of avian basal metabolic rate: good predictions need good data. Physiol Biochem Zool PBZ 77(3):502-521. https://doi.org/10.1086/383511

McKechnie AE, Wolf BO (2004b) Partitioning of evaporative water loss in white-winged doves: plasticity in response to short-term thermal acclimation. J Exp Biol 207(2):203-210. https://doi. org/10.1242/jeb.00757

McKechnie AE, Wolf BO (2010) Climate change increases the likelihood of catastrophic avian mortality events during extreme heat waves. Biol Lett 6(2):253-256. https://doi.org/10.1098/ rsbl.2009.0702

McKechnie AE, Wolf BO (2019) The physiology of heat tolerance in small endotherms. Physiol (Beth) 34(5):302-313. https://doi. org/10.1152/physiol.00011.2019

Meehl GA, Tebaldi C (2004) More intense, more frequent, and longer lasting heat waves in the 21 st century. Science 305(5686):994 997. https://doi.org/10.1126/science.1098704

Muñoz-Garcia A, Cox RM, Williams JB (2008) Phenotypic flexibility in cutaneous water loss and lipids of the stratum corneum in house sparrows (Passer domesticus) following acclimation to high and low humidity. Physiol Biochem Zool PBZ 81(1):87-96. https:// doi.org/10.1086/522651

Nespolo RF, Bacigalupe LD, Rezende EL, Bozinovic F (2001) When nonshivering thermogenesis equals maximum metabolic rate: thermal acclimation and phenotypic plasticity of fossorial Spalacopus cyanus (Rodentia). Physiol Biochem Zool 74(3):325-332

Noakes MJ, McKechnie AE (2019) Reaction norms for heat tolerance and evaporative cooling capacity do not vary across a climatic gradient in a passerine bird. Comp Biochem Physiol A Mol Integr Physiol. https://doi.org/10.1016/j.cbpa.2019.06.022

Noakes MJ, McKechnie AE (2020) Phenotypic flexibility of metabolic rate and evaporative water loss does not vary across a climatic gradient in an Afrotropical passerine bird. J Exp Biol. https://doi. org/10.1242/jeb.220137

Noakes MJ, Wolf BO, McKechnie AE (2016) Seasonal and geographical variation in heat tolerance and evaporative cooling capacity in a passerine bird. J Exp Biol 219(Pt 6):859-869. https://doi. org/10.1242/jeb.132001

O'Connor RS, Wolf BO, Brigham RM, McKechnie AE (2017) Avian thermoregulation in the heat: efficient evaporative cooling in two southern African nightjars. J Comp Physiol [B] 187(3):477-491. https://doi.org/10.1007/s00360-016-1047-4

Oswald KN, Lee ATK, Smit B (2018) Seasonal physiological responses to heat in an alpine range-restricted bird: the Cape Rockjumper (Chaetops frenatus). J Ornithol. https://doi.org/10.1007/s1033 6-018-1582-8

Oosterbaan RJ, Sharma DP, Singh KN (1990) Crop production and soil salinity: evaluation of field data from India by segmented linear regression. Symp Land Drain Salin Control Arid Semi-Arid Reg 3:373-382

Pattinson NB, Thompson ML, Griego M, Russell G, Mitchell NJ, Martin RO, Wolf BO, Smit B, Cunningham SJ, McKechnie AE, Hockey PAR (2020) Heat dissipation behaviour of birds in seasonally hot, arid-zones: are there global patterns? J Avian Biol. https ://doi.org/10.1111/jav.02350

Piersma T, Van Gils JA (2011) The flexible phenotype: a body-centred integration of ecology, physiology, and behaviour. Oxford University Press, Oxford

R Core Team (2020) R: A Language and Environment for Statistical Computing. R Foundation for Statistical Computing. Vienna, Austria. https://www.R-project.org/. Accessed May 2020

Riddell EA, Iknayan KJ, Wolf BO, Sinervo B, Beissinger SR (2019) Cooling requirements fueled the collapse of a desert bird community from climate change. Proc Natl Acad Sci USA. https:// doi.org/10.1073/pnas.1908791116

Rønning B, Jensen H, Moe B, Bech C (2007) Basal metabolic rate: heritability and genetic correlations with morphological traits in the zebra finch. J Evol Biol 20(5):1815-1822. https://doi.org /10.1111/j.1420-9101.2007.01384.x

Rønning B, Moe B, Bech C (2005) Long-term repeatability makes basal metabolic rate a likely heritable trait in the zebra finch Taeniopygia guttata. J Exp Biol 208(Pt 24):4663-4669. https ://doi.org/10.1242/jeb.01941

Rutkowska J, Sadowska ET, Cichoń M, Bauchinger U (2016) Increased fat catabolism sustains water balance during fasting in zebra finches. The Journal of experimental biology 219(17):2623-2628. https://doi.org/10.1242/jeb.138966

Scholander PF, Hock R, Walters V, Johnson F, Irving L (1950) Heat regulation in some arctic and tropical mammals and birds. Biol Bull-Us 99(2):237-258

Schmidt-Nielsen K (1997) Animal physiology: adaptation and environment. Cambridge University Press, Cambridge

Smit B, Zietsman G, Martin RO, Cunningham SJ, McKechnie AE, Hockey PAR (2016) Behavioural responses to heat in desert birds: implications for predicting vulnerability to climate warming. Clim Change Respon. https://doi.org/10.1186/s4066 5-016-0023-2

Stoffel MA, Nakagawa S, Schielzeth H (2017) rptR: repeatability estimation and variance decomposition by generalized linear mixed-effects models. Methods Ecol Evol 8:1639-1644. https ://doi.org/10.1111/2041-210X.12797

Swanson DL (2010) Seasonal metabolic variation in birds: functional and mechanistic correlates. Curr Ornithol 17:75-129. https:// doi.org/10.1007/978-1-4419-6421-2_3

Tieleman BI, Williams JB (1999) The role of hyperthermia in the water economy of desert birds. Physiol Biochem Zool PBZ 72(1):87-100. https://doi.org/10.1086/316640

Tieleman BI, Williams JB (2002) Cutaneous and respiratory water loss in larks from arid and mesic environments. Physiol Biochem Zool PBZ 75(6):590-599. https://doi.org/10.1086/344491

Tieleman BI, Williams JB, Buschur ME (2002) Physiological adjustments to arid and mesic environments in larks (Alaudidae). Physiol Biochem Zool 75(3):305-313. https://doi. org/10.1086/341998

Tieleman BI, Williams JB, Buschur ME, Brown CR (2003) Phenotypic variation of larks along an aridity gradient: are desert birds more 
flexible? Ecology 84(7):1800-1815. https://doi.org/10.1890/00129658(2003)084[1800:Pvolaa]2.0.Co;2

Tieleman BI, Williams JB, LaCroix F, Paillat P (2002) Physiological responses of Houbara bustards to high ambient temperatures. J Exp Biol 205(Pt 4):503-511

Tracy CR, Welch WR, Pinshow B, Porter WP (2010) Properties of air: a manual for use in biophysical ecology. 4th Ed. The University of Wisconsin Laboratory for Biophysical Ecology: Technical Report 4

Vezina F, Gerson AR, Guglielmo CG, Piersma T (2017) The performing animal: causes and consequences of body remodeling and metabolic adjustments in red knots facing contrasting thermal environments. Am J Physiol Regul Integr Comp Physiol 313(2):R120-R131. https://doi.org/10.1152/ajpregu.00453.2016

Vezina F, Jalvingh KM, Dekinga A, Piersma T (2006) Acclimation to different thermal conditions in a northerly wintering shorebird is driven by body mass-related changes in organ size. J Exp Biol 209(Pt 16):3141-3154. https://doi.org/10.1242/jeb.02338

Walsberg GE, King JR (1978) The relationship of the external surface area of birds to skin surface area and body mass. J Exp Biol 76(1):185-189

Welbergen JA, Klose SM, Markus N, Eby P (2008) Climate change and the effects of temperature extremes on Australian flying-foxes. Proc Biol Sc R Soc 275(1633):419-425. https://doi.org/10.1098/ rspb.2007.1385
Whitfield MC, Smit B, McKechnie AE, Wolf BO (2015) Avian thermoregulation in the heat: scaling of heat tolerance and evaporative cooling capacity in three southern African arid-zone passerines. J Exp Biol 218(Pt 11):1705-1714. https://doi.org/10.1242/ jeb. 121749

Williams JB, Tieleman BI (2000) Flexibility in basal metabolic rate and evaporative water loss among hoopoe larks exposed to different environmental temperatures. J Exp Biol 203(20):3153-3159

Williams JB, Tieleman BI (2002) Ecological and evolutionary physiology of desert birds: a progress report. Integr Comp Biol 42(1):6875. https://doi.org/10.1093/icb/42.1.68

Williams JB, Tieleman BI (2005) Physiological Adaptation in Desert Birds. BioScience. https://doi.org/10.1641/00063568(2005)055[0416:Paidb]2.0.Co;2

Wolf BO, Walsberg GE (1996) Respiratory and cutaneous evaporative water loss at high environmental temperatures in a small bird. $\mathrm{J}$ Exp Biol 199(2):451-457

Wood, S.N. (2006) Generalized additive models: an introduction with R. Chapman and Hall/CRC

Zann RA (1996) The zebra finch: a synthesis of field and laboratory studies, vol 5. Oxford University Press, Oxford

Publisher's Note Springer Nature remains neutral with regard to jurisdictional claims in published maps and institutional affiliations. 